\title{
Dynamic interaction of hTRPC6 with the Orai1/STIM1 complex or hTRPC3 mediates its role in capacitative or non-capacitative $\mathrm{Ca}^{2+}$ entry pathways
}

\author{
I. Jardin, L. J. Gómez, G. M. Salido and Juan A. Rosado
}

Department of Physiology (Cellular Physiology Research Group), University of

Extremadura, 10071 Caceres, Spain

Running Title: Role of hTRPC6 in capacitative and non-capacitative $\mathrm{Ca}^{2+}$ entry

Address correspondence to: Dr. J. A. Rosado, Department of Physiology, University of Extremadura, Caceres 10071, SPAIN, Tel: +34 927257154; Fax:+34 927257110; E-mail: jarosado@unex.es

\begin{abstract}
TRPC channel subunits have been shown to assemble into homo- or heteromeric channel complexes, including different $\mathrm{Ca}^{2+}$-handling proteins, required for the activation of capacitative $\mathrm{Ca}^{2+}$ entry (CCE) or non-capacitative $\mathrm{Ca}^{2+}$ entry (NCCE) pathways. Here we present evidence for the dynamic interaction between endogenously expressed hTRPC6 with either both Orai1 and STIM1 or hTRPC3 to participate in CCE or NCCE. Electrotransjection of cells with anti-hTRPC6 antibody, directed towards the C-terminal region, reduces CCE induced by N,N,N',N'-tetrakis-(2-pyridylmethyl)-ethylenediamine (TPEN), which reduces intraluminal free $\mathrm{Ca}^{2+}$ concentration. Cell stimulation with thrombin or extensive $\mathrm{Ca}^{2+}$ store depletion by thapsigargin (TG) + Iono enhanced interaction between hTRPC6 and the CCE proteins Orai1 and STIM1. In contrast, stimulation with the diacylglycerol analogue 1oleoyl-2-acetyl-sn-glycerol (OAG) displaces hTRPC6 from Orai1 and STIM1 and enhances the association between hTRPC6 and hTRPC3. The interaction between hTRPC6 and hTRPC3 was abolished by dimethyl-BAPTA loading, which indicate that this phenomenon is $\mathrm{Ca}^{2+}$-dependent. These findings support that hTRPC6 participate both in CCE and NCCE through its interaction with the Orai1/STIM1 complex or hTRPC3, respectively.
\end{abstract}

Key words. hTRPC6, STIM1, Orai1, hTRPC3, calcium entry, thrombin, platelets. 


\section{INTRODUCTION}

The canonical transient receptor potential (TRPC) cation channels are mammalian homologues of the photoreceptor TRP channel in Drosophila melanogaster [1]. A number of evidences have supported the role of TRPC channels in both capacitative $\mathrm{Ca}^{2+}$ entry (CCE) and non-capacitative $\mathrm{Ca}^{2+}$ entry (NCCE) pathways [2-5].

The identification of the endoplasmic reticulum (ER) $\mathrm{Ca}^{2+}$ sensor STIM1 and the plasma membrane (PM) $\mathrm{Ca}^{2+}$ channel Orai1 has shed new light on the mechanism of activation of CCE. Orai1 forms a highly $\mathrm{Ca}^{2+}$ selective channel that has been proposed to conduct $\mathrm{I}_{\mathrm{CRAC}}$ [6]. Orai1 has been reported to participate in the formation of multimeric ion-channel complexes involving hTRPC1 and STIM1 [7, 8]. STIM1 is a low affinity $\mathrm{Ca}^{2+}$-binding protein mostly located in the ER membrane that contains an EF-hand domain in the $\mathrm{NH}_{2}$ terminus, located in the lumen of the ER, that has been proposed to function as a $\mathrm{Ca}^{2+}$ sensor in the ER [9, 10], conferring TRPC1 protein store-operated sensitivity [8].

hTRPC6 has been presented as a component of NCCE, as well as CCE, channels. hTRPC6 was initially presented as a channel activated by diacylglycerol (DAG) generated by receptor-induced phosholipase $C$ activation [11, 12]. Furthermore, in human platelets, heteromeric interaction of hTRPC6 with hTRPC1 forms a complex activated by depletion of the intracellular $\mathrm{Ca}^{2+}$ stores [13]. Consistent with this, we have previously reported that hTRPC6 is required for thapsigargin (TG)-mediated $\mathrm{Ca}^{2+}$ entry in platelets [4]. In addition, in smooth muscle cells, hTRPC6 channels are activated by mechanical stretch, leading to membrane depolarization and the activation of voltage-dependent $\mathrm{Ca}^{2+}$ entry [14]. Therefore, TRPC6-forming channels function as integrators of a number of intracellular signals.

There is significant controversy concerning the mode of activation (capacitative or noncapacitative) of particular TRPC channel subunits [15]. These discrepancies might at least be partially attributed to the tetrameric composition of TRPC channels. Thus, different combinations of TRPC subunits might lead to the formation of channels with different biophysical properties. The assembly of a particular combination of TRPC subunits might be performed in situ under an adequate stoichiometric relationship, conditions that might be altered in TRPC-overexpressing cells [15], which supports the importance of experiments in cells endogenously expressing TRPC proteins.

In HEK-293 cells expressing TRPC3, TRPC6 and the three Orai isoforms, interaction of Orai proteins with both TRPC proteins has been reported to confer them the ability to respond to store depletion [16].

In the present study we have investigated the interaction of endogenously expressed hTRPC6 with components of the CCE and NCCE pathways at resting conditions and upon store depletion either by pharmacological tools or the physiological agonist thrombin or after stimulation with the diacylglycerol analogue OAG. Our results indicate that $\mathrm{Ca}^{2+}$ store depletion stimulates rapid interaction between hTRPC6 and both, Orai1 and STIM1, while stimulation with the NCCE inducer OAG evokes the displacement of hTRPC6 from the CCE pathway and promotes its interaction with the NCCE $\mathrm{Ca}^{2+}$ permeable channel, hTRPC3.

\section{MATERIAL AND METHODS}

\section{Materials}

Fura-2 acetoxymethyl ester (fura-2/AM) and calcein-AM were from Molecular Probes (Leiden, The Netherlands). Apyrase (grade VII), aspirin, thapsigargin (TG), thrombin, phenylmethanesulphonylfluoride (PMSF) and bovine serum albumin (BSA) were from Sigma (Madrid, Spain). Ionomycin (Iono), N,N,N',N'-tetrakis-(2-pyridylmethyl)ethylenediamine (TPEN) and 1-oleoyl-2-acetyl-sn-glycerol (OAG) were from Calbiochem 
(Nottingham, U.K.). Goat anti-hTRPC6 polyclonal antibody, horseradish peroxidaseconjugated goat anti-rabbit IgG antibody and horseradish peroxidase-conjugated donkey anti-goat IgG antibody were from Santa Cruz (Santa Cruz, CA, U.S.A.). Rabbit anti-TRPC1 antibody was from Alomone Labs (Jerusalem, Israel). Rabbit anti-TRPC3 polyclonal antibody was from Abcam (Cambridge, U.K.). Rabbit anti-Orai1 antibody was from ProSci (Poway, CA, U.S.A.). Mouse anti STIM1 antibody was from BD Transduction Laboratories (Frankin Lakes, NJ, U.S.A.). Hyperfilm ECL was from Amersham (Buckinghamshire, U.K.). Protein A-agarose was from Upstate Biotechnology Inc. (Madrid, Spain). Enhanced chemiluminescence detection reagents and rabbit anti-mouse IgG were from Pierce (Cheshire, U. K.). All other reagents were of analytical grade.

\section{Platelet Preparation}

Fura-2-loaded platelets were prepared as previously described [17] as approved by Local Ethical Committees and in accordance with the Declaration of Helsinki. Briefly, blood was obtained from healthy drug-free volunteers and mixed with one-sixth volume of acid/citrate dextrose anticoagulant containing (in $\mathrm{mM}$ ): 85 sodium citrate, 78 citric acid and $111 \mathrm{D}$ glucose. Platelet-rich plasma (PRP) was then prepared by centrifugation for $5 \mathrm{~min}$ at $700 \mathrm{~g}$ and aspirin $(100 \mu \mathrm{M})$ and apyrase $(40 \mu \mathrm{g} / \mathrm{mL})$ were added. Platelet-rich plasma was incubated at $37{ }^{\circ} \mathrm{C}$ with $2 \mu \mathrm{M}$ fura-2 acetoxymethyl ester for $45 \mathrm{~min}$. Cells were then collected by centrifugation at $350 \mathrm{~g}$ for $20 \mathrm{~min}$ and resuspended in HEPES-buffered saline (HBS), pH 7.45, containing (in mM): 145 NaCl, 10 HEPES, 10 D-glucose, 5 KCl, 1 MgSO4 and supplemented with $0.1 \%$ BSA and $40 \mu \mathrm{g} / \mathrm{mL}$ apyrase.

\section{Cell viability}

Cell viability was assessed using calcein and trypan blue. For calcein loading, cells were incubated for $30 \mathrm{~min}$ with $5 \mu \mathrm{M}$ calcein-AM at $37{ }^{\circ} \mathrm{C}$, centrifuged and the pellet was resuspended in fresh HBS. Fluorescence was recorded from $2 \mathrm{~mL}$ aliquots using a Cary Eclipse Spectrophotometer (Varian Ltd, Madrid, Spain). Samples were excited at $494 \mathrm{~nm}$ and the resulting fluorescence was measured at $535 \mathrm{~nm}$. The results obtained with calcein were confirmed using the trypan blue exclusion technique.

\section{Measurement of cytosolic free calcium concentration ( $\left.\left[\mathrm{Ca}^{2+}\right]_{\mathrm{c}}\right)$}

Fluorescence was recorded from $2 \mathrm{~mL}$ aliquots of magnetically stirred platelet suspension (2 $\times 10^{8}$ cells $/ \mathrm{mL}$ ) at $37{ }^{\circ} \mathrm{C}$ using a fluorescence spectrophotometer with excitation wavelengths of 340 and $380 \mathrm{~nm}$ and emission at $505 \mathrm{~nm}$. Changes in $\left[\mathrm{Ca}^{2+}\right]_{\mathrm{c}}$ were monitored using the fura-2 340/380 fluorescence ratio and, when TPEN was absent, calibrated according to the method of Grynkiewicz et al. [18].

$\mathrm{Ca}^{2+}$ entry was estimated using the integral of the rise in $\left[\mathrm{Ca}^{2+}\right]_{\mathrm{c}}$ for $2.5 \mathrm{~min}$ after addition of $\mathrm{CaCl}_{2}$ [19]. Control experiments were performed for all experimental procedures in order to correct the amount of $\mathrm{Ca}^{2+}$ entry (integrals) by subtraction of the integral of the $\left[\mathrm{Ca}^{2+}\right]_{\mathrm{c}}$ elevation due to leakage of the indicator. $\mathrm{Ca}^{2+}$ release from the intracellular stores was estimated using the integral of the rise in $\left[\mathrm{Ca}^{2+}\right]_{\mathrm{c}}$ for 3 min after the addition of thrombin.

\section{Reversible Electroporation Procedure}

The platelet suspension was transferred to an electroporation chamber containing antibodies at a final concentration of $2 \mu \mathrm{g} / \mathrm{mL}$, and the antibodies were transjected according to published methods $[4,20]$. Reversible electropermeabilization was performed at $4 \mathrm{kV} / \mathrm{cm}$ at a setting of 25-microfarad capacitance and was achieved by 7 pulses using a Bio-Rad Gene Pulser Xcell Electroporation System (Bio-Rad, Hercules, CA, U.S.A.). Following 
electroporation, cells were incubated with antibodies for an additional $60 \mathrm{~min}$ at $37^{\circ} \mathrm{C}$ then were centrifuged at $350 \mathrm{~g}$ for $20 \mathrm{~min}$ and resuspended in $\mathrm{HBS}$ containing $200 \mu \mathrm{M} \mathrm{CaCl}_{2}$. At the time of experiment $250 \mu$ M EGTA was added.

\section{Immunoprecipitation and Western blotting}

The immunoprecipitation and Western blotting were performed as described previously [21]. Briefly, $500 \mu \mathrm{L}$ aliquots of platelet suspension $\left(2 \times 10^{9}\right.$ cell $\left./ \mathrm{mL}\right)$ were lysed with an equal volume of RIPA buffer, $\mathrm{pH}$ 7.2, containing $316 \mathrm{mM} \mathrm{NaCl,} 20 \mathrm{mM}$ Tris, 2 mM EGTA, $0.2 \%$ SDS, $2 \%$ sodium deoxycholate, $2 \%$ triton X-100, 2 mM Na $3 \mathrm{VO}_{4}, 2$ mM PMSF, $100 \mu \mathrm{g} / \mathrm{mL}$ leupeptin and $10 \mathrm{mM}$ benzamidine. Aliquots of platelet lysates $(1 \mathrm{~mL})$ were immunoprecipitated by incubation with $2 \mu \mathrm{g}$ of either anti-Orai1, anti-TRPC 3 or antiTRPC6 antibody and $25 \mu \mathrm{L}$ of protein A-agarose overnight at $4{ }^{\circ} \mathrm{C}$ on a rocking platform. The immunoprecipitates were resolved by $10 \%$ SDS-PAGE and separated proteins were electrophoretically transferred onto nitrocellulose membranes for subsequent probing. Blots were incubated overnight with $10 \%$ (w/v) BSA in tris-buffered saline with $0.1 \%$ Tween 20 (TBST) to block residual protein binding sites. Immunodetection of STIM1, hTRPC3, hTRPC6 and Orai1 was achieved using the anti-STIM1 antibody diluted 1:250 in TBST for $2 \mathrm{~h}$ or the anti-hTRPC3, anti-hTRPC6 or anti-Orai1 antibody diluted 1:1000 in TBST for 2h, respectively. The primary antibody was removed and blots were washed six times for 5 min each with TBST. To detect the primary antibody, blots were incubated for 45 min with horseradish peroxidase-conjugated donkey anti-goat IgG antibody, horseradish peroxidaseconjugated rabbit anti-mouse IgG antibody or horseradish peroxidase-conjugated goat antirabbit IgG antibody diluted $1: 10000$ in TBST and then exposed to enhanced chemiluminiscence reagents for $4 \mathrm{~min}$. Blots were then exposed to photographic films. The density of bands on the film was measured using scanning densitometry. Data were normalized to the amount of protein recovered by the antibody used for the immunoprecipitation.

\section{Statistical Analysis}

Analysis of statistical significance was performed using one-way analysis of variance. For comparison between two groups Student's $t$ test was used. $P<0.05$ was considered to be significant for a difference.

\section{RESULTS}

\section{hTRPC6 co-immunoprecipitates with STIM1 and Orai1 in human platelets}

A role for endogenously expressed hTRPC6 in agonist-induced $\mathrm{Ca}^{2+}$ entry has been demonstrated in human platelets $[4,12]$. We have now investigated the association between hTRPC6 and both, STIM1 and Orai1, by looking for co-immunoprecipitation from platelet lysates. Immunoprecipitation and subsequent SDS-PAGE and Western blotting were conducted using resting platelets and platelets stimulated in the absence of extracellular $\mathrm{Ca}^{2+}$ (100 $\mu \mathrm{M}$ EGTA was added to the extracellular medium) with the physiological agonist thrombin $(1 \mathrm{U} / \mathrm{mL})$ or with the inhibitor of the sarcoendoplasmic reticulum $\mathrm{Ca}^{2+}$-ATPase (SERCA) TG $(1 \mu \mathrm{M})$ plus a low concentration of Iono (50 $\mathrm{nM})$, to induce extensive depletion of the intracellular stores in platelets [22]. After treatment with these agents cell viability in our platelet preparations was estimated as 95\%. After immunoprecipitation with anti-hTRPC6 antibody, Western blotting with anti-STIM1 antibody revealed a band between 84 and $90 \mathrm{kDa}$ (the predicted molecular weight of STIM1 [23]) in samples from resting platelets (Figure 1A, upper panel). Treatment with thrombin increased the association 
between STIM1 and hTRPC6 in a time-dependent manner, reaching a maximal effect after $30 \mathrm{~s}$ of platelet stimulation (Figure 1A, upper panel; $n=6$ ). In addition, we have investigated the possible interaction between hTRPC6 and Orai1. After immunoprecipitation with antihTRPC6 antibody, Western blotting with anti-Orai1 antibody revealed a band of approximately $45 \mathrm{kDa}$ (the predicted molecular weight of Orai1 [24]) in samples from resting platelets (Figure 1B, upper panel). Treatment with thrombin enhanced the coimmunoprecipitation of hTRPC6 with Orai1 in a time-dependent manner (Figure 1B, upper panel; $n=6)$. Similar results were observed when cells were stimulated with $\mathrm{TG}+\mathrm{Iono}$, which increased coimmunoprecipitation of hTRPC6 with STIM1 and Orai1 in a time-dependent manner, reaching a maximum after $10 \mathrm{~s}$ of stimulation, and then was sustained for at least 60 $\mathrm{s}$ (Figure 2A and $\mathrm{B}$, upper panel; $n=6$ ). We also conducted converse experiments, immunoprecipitating platelet lysates with anti-STIM1 or anti-Orai1 antibodies and detecting for the presence of hTRPC6, a protein of approximately $100 \mathrm{kDa}$ [25]. Under these conditions, treatment with thrombin or TG+Iono enhanced the association of hTRPC6 with STIM1 in a time-dependent manner, with a $148 \pm 24,195 \pm 34$ and $179 \pm 37 \%$ of control for thrombin and $143 \pm 18,155 \pm 31$ and $126 \pm 31 \%$ of control for TG+Iono at 10, 30 and $60 \mathrm{~s}$, respectively. Similarly, both agents enhanced the association between hTRPC6 and Orai1 with a $115 \pm 6,150 \pm 22$ and $180 \pm 40 \%$ of control for thrombin and $135 \pm 17,158 \pm 16$ and $131 \pm 21 \%$ of control for TG+Iono at 10,30 and 60 s, respectively (Figures 1 and 2, C and D upper panels). Western blotting of the same membranes with the antibody used for immunoprecipitation confirmed similar protein content in all lanes (Figures 1 and 2, lower panels). No specific proteins were detected when immunoprecipitation was performed using a non-specific rabbit IgG control. Only the heavy chain of the rabbit IgG used for immunoprecipitation was detected when a horseradish peroxidase-conjugated anti-rabbit IgG was used as secondary antibody in lanes 3 to 5 (Supplementary Figure 1).

\section{hTRPC6 is involved in TPEN-mediated $\mathrm{Ca}^{2+}$ entry}

TPEN may be a useful tool to investigate the mechanism of CCE due to its ability to reduce intraluminal free $\mathrm{Ca}^{2+}$ concentration. The use of TPEN avoids potential confounders, such as changes in cytosolic $\mathrm{Ca}^{2+}$ and second messenger levels, secondary to stimulation with agonists, as well as the use of pharmacological inhibitors of SERCA, which has been suggested to play a role in CCE [26]. In a $\mathrm{Ca}^{2+}$-free medium, treatment of fura-2-loaded human platelets with thrombin $(1 \mathrm{U} / \mathrm{mL})$ in stirred cuvettes at $37{ }^{\circ} \mathrm{C}$ evoked a transient elevation in $\left[\mathrm{Ca}^{2+}\right]_{\mathrm{c}}$ due to $\mathrm{Ca}^{2+}$ release from internal stores. Subsequent addition of $300 \mu \mathrm{M}$ $\mathrm{Ca}^{2+}$ to the external medium induced a sustained increase in $\left[\mathrm{Ca}^{2+}\right]_{\mathrm{c}}$ (Figure 3A upper graph; $\mathrm{n}=5$ ). TPEN is a membrane-permeant multivalent cation chelator, that shows moderate affinity for $\mathrm{Ca}^{2+}$ ( $\mathrm{Kd}$ for $\mathrm{Ca}^{2+} \sim 130 \mu \mathrm{M}$ ), which has been used to rapidly and reversibly chelate $\mathrm{Ca}^{2+}$ within the intracellular stores [27]. In the absence of extracellular $\mathrm{Ca}^{2+}$, the addition of $500 \mu \mathrm{M}$ TPEN to human platelets did not modify $\left[\mathrm{Ca}^{2+}\right]_{c}$; subsequent addition of $300 \mu \mathrm{M} \mathrm{Ca}^{2+}$ to the external medium induced a sustained elevation in $\left[\mathrm{Ca}^{2+}\right]_{\mathrm{c}}$ indicative of SOCE [28], due to in situ chelation of $\mathrm{Ca}^{2+}$ in the intracellular stores (Figure 3A upper graph; $\mathrm{n}=5$ ). The elevation in Fura-2 fluorescence ratio observed after the addition of $\mathrm{Ca}^{2+}$ to the medium in the presence of TPEN was clearly greater than that observed in the absence of TPEN (Figure 3A lower graph; $\mathrm{n}=5$ ). In the presence of TPEN, thrombin-evoked $\mathrm{Ca}^{2+}$ release and entry were significantly reduced (Figure 3A upper graph), a phenomenon that is not likely attributed to a decrease in cell viability (95\% of cells were viable in our platelet preparations treated with TPEN, at least during the performance of the experiments).

To investigate the involvement of hTRPC6 in TPEN-mediated CCE we have induced functional knock down of hTRPC6 by electrotransjection of cells with anti-hTRPC6 
antibody, directed towards an intracellular C-terminal sequence, following a previously described procedure [4]. Platelet viability after reversible electroporation was $90 \%$; therefore experimental cells and controls were treated in the same way, except for the antibody electrotransjected (anti-hTRPC3 or hTRPC6 antibodies in experimental cells and a nonspecific rabbit IgG in controls). We have recently reported that platelet incubation with the anti-hTRPC6 antibody reduced $\mathrm{Ca}^{2+}$ and $\mathrm{Mn}^{2+}$ entry induced by thrombin, TG or 2,5-di(tert-butyl)-1,4-hydroquinone, thus suggesting a role for hTRPC6 in CCE [4]. Here we show for the first time that electrotransjection with $1 \mu \mathrm{g} / \mathrm{mL}$ hTRPC6 significantly reduced TPENevoked CCE by $33 \pm 6 \%$ compared to controls (cells electrotransjected with $1 \mu \mathrm{g} / \mathrm{mL}$ goat IgG; Figure 3B upper graph; $P<0.05$; $n=5$ ). We have further explored the role of hTRPC3 in CCE induced by TPEN by electrotransjection of cells with anti-hTRPC3 antibody directed towards the intracellular $\mathrm{NH}_{2}$-terminal sequence. As shown in Figure 3B upper graph, TPEN-evoked CCE was not modified in cells electrotransjected with $1 \mu \mathrm{g} / \mathrm{mL}$ anti-hTRPC3 antibody compared to platelets electrotransjected with $1 \mu \mathrm{g} / \mathrm{mL}$ rabbit IgG. Finally, we found that electrotransjection of the anti-hTRPC6 antibody in combination with antihTRPC3 antibody reduced CCE by TPEN to a similar extent as the anti-hTRPC6 antibody alone (Figure 3B upper graph).

As mentioned in material and methods, the amount of $\mathrm{Ca}^{2+}$ entry was corrected by subtraction of the elevation in $\left[\mathrm{Ca}^{2+}\right]_{\mathrm{c}}$ observed after the addition of $\mathrm{Ca}^{2+}$ in cells treated with vehicle instead of thrombin and/or TPEN (Figure 3A and B lower graphs).

\section{$\mathrm{Ca}^{2+}$-dependent association of hTRPC6 and hTRPC3}

We have further investigated the interaction between hTRPC6 and hTRPC3 upon stimulation with thrombin or TG + Iono. Immunoprecipitation with anti-hTRPC6 antibody followed by Western blotting with anti-hTRPC3 antibody revealed a band of approximately $100 \mathrm{kDa}$ (the predicted molecular weight of hTRPC3 [29]), which indicates association of both hTRPC proteins in resting platelets (Figure 4 upper panels). In the absence of extracellular $\mathrm{Ca}^{2+}$, platelet stimulation with thrombin or extensive $\mathrm{Ca}^{2+}$ store depletion, induced by TG + Iono, enhanced co-immunoprecipitation between hTRPC6 and hTRPC3 (Figure 4A and $\mathrm{B}$ upper panels; $P<0.05$ ). This effect was abolished by platelet loading with the intracellular $\mathrm{Ca}^{2+}$ chelator dimethyl BAPTA, which prevents thrombin-, as well as TG + Iono-induced $\mathrm{Ca}^{2+}$ elevations in $\left[\mathrm{Ca}^{2+}\right]_{\mathrm{c}}$ (Figure 4C-F). Similar results were observed when converse experiments were conducted immunoprecipitating platelet lysates with antihTRPC3 antibody and detecting for the presence of hTRPC6. Treatment with thrombin or TG+Iono enhanced the association of hTRPC 6 with hTRPC3 by $142 \pm 8$ and $151 \pm 11 \%$ of control, respectively (Figure 4A and B, lower panels). This event was prevented by BAPTA loading (Figure 4E and F, lower panels).

Interestingly, we have found that OAG, a DAG analogue that activates NCCE, attenuates the association between hTRPC6 and both, Orai1 and STIM1, as detected by immunoprecipitation of platelet lysates with anti-hTRPC6 antibody followed by Western blotting with anti-Orai1 or anti-STIM1 antibodies (Figure $5 \mathrm{~A}$ and $\mathrm{B}$, upper panels; $P<0.05$ ) as well as by converse experiments (Figure $5 \mathrm{~A}$ and $\mathrm{B}$, lower panels; $P<0.05$ ). In the absence of extracellular $\mathrm{Ca}^{2+}$, OAG was unable to induce association between hTRPC6 and hTRPC3 (Figure $5 \mathrm{C}$ ). In contrast, in the presence of $1 \mathrm{mM}$ extracellular $\mathrm{Ca}^{2+} \mathrm{OAG}$ significantly enhanced association between both hTRPC proteins (Figure 5D; $P<0.05$ ). Western blotting of the same membranes with the anti-hTRPC6 antibody confirmed comparable amounts of protein in all lanes (Figures 4 and 5).

As shown in Figure 5E upper graph, treatment of platelets in a $\mathrm{Ca}^{2+}$-free medium with 100 
$\mu$ M OAG did not increase $\left[\mathrm{Ca}^{2+}\right]_{c}$; subsequent addition of $\mathrm{Ca}^{2+}$ to the external medium resulted in a rise in $\left[\mathrm{Ca}^{2+}\right]_{\mathrm{c}}$, greater than that induced in cells treated with vehicle alone (Figure 5E lower graph), indicative of NCCE. Electrotransjection with $1 \mu \mathrm{g} / \mathrm{mL}$ hTRPC3 or hTRPC6 significantly reduced OAG-evoked NCCE by $40 \pm 9$ and $56 \pm 2 \%$, respectively (Figures 5G and $\mathrm{H}$ ) compared to controls (cells electrotransjected with $1 \mu \mathrm{g} / \mathrm{mL}$ rabbit IgG; Figure $5 \mathrm{~F}(\alpha$-mouse $\operatorname{Ig} G) ; P<0.05 ; \mathrm{n}=5)$. Altogether, these findings suggest that the association of hTRPC6 and hTRPC3 induced by OAG is mediated by a $\mathrm{Ca}^{2+}$-dependent mechanism, as previously described for the association between both proteins stimulated by thrombin or TG + Iono.

\section{Treatment with TG + ionomycin is unable to induce association of hTRPC3 with hTRPC1, STIM1 or Orai1}

We have further investigated the possible interaction between hTRPC3 and hTRPC1, STIM1 and Orai1, which form a dynamic complex involved in CCE [30], upon stimulation with TG + Iono. Immunoprecipitation with anti-hTRPC3 antibody followed by Western blotting with anti-hTRPC1 antibody revealed a faint band of approximately $100 \mathrm{kDa}$ (the predicted molecular weight of hTRPC1 [31, 32]), which indicates certain association of both hTRPC proteins in resting platelets (Figure 6A upper panel; $n=5$ ). After platelet stimulation with TG + Iono the amount of hTRPC1 immunoprecipitated with the anti-hTRPC3 antibody was not significantly different from than observed in resting cells (Figure 6A upper panel). No protein with the predicted molecular weight of STIM1 of Orai1 were detected in hTRPC3 immunoprecipitates either in resting or in TG+Iono-stimulated cells (Figure 6B and C, upper panels; $\mathrm{n}=5)$. Similar results were observed when converse experiments were conducted immunoprecipitating platelet lysates with anti-hTRPC1, anti-STIM1 or anti-Orai1 antibody and detecting for the presence of hTRPC3 (Figure 6 lower panels).

\section{DISCUSSION}

Canonical TRP proteins have been shown to participate both in capacitative and noncapacitative $\mathrm{Ca}^{2+}$ influx [15]. hTRPC6 has long been proposed as a candidate to mediate NCCE in different cell types [11,33,34], including human platelets [12]. In these cells, we have recently suggested that hTRPC6 might also be involved in the conduction of CCE on the base of the inhibitory effect of electrotransjection of the anti-hTRPC6 antibody on TGinduced $\mathrm{Ca}^{2+}$ entry [4]. CCE is a mechanism for $\mathrm{Ca}^{2+}$ influx regulated by the $\mathrm{Ca}^{2+}$ content of the intracellular stores rather than by the $\mathrm{Ca}^{2+}$ signals generated by agonists or pharmacological tools like TG [35]. Here we have further observed the involvement of hTRPC6 in CCE by using TPEN, an intracellular $\mathrm{Ca}^{2+}$ chelator that reduces free $\mathrm{Ca}^{2+}$ concentration in the intracellular stores $\left(\left[\mathrm{Ca}^{2+}\right]_{\mathrm{s}}\right)$ without changes in $\left[\mathrm{Ca}^{2+}\right]_{\mathrm{c}}$ secondary to stimulation with agonists or TG, which confirms previous results [4]. We have found that hTRPC3, which has been shown to conduct CCE in a number of cell types [36, 37] but NCCE in others [38, 39], is not required for $\mathrm{Ca}^{2+}$ entry induced by TPEN, as demonstrated by electrotransjection of the anti-hTRPC3 antibody, which further suggest that treatment with TPEN induces CCE in human platelets. The specificity of electrotransjection with antibodies has been explored by testing the effect of incubation with an antibody directed to a protein not related to hTRPC6 or hTRPC3 proteins or any other platelet protein. We have used goat or rabbit IgG since these are the natures of the anti-hTRPC6 and anti-hTRPC3 antibodies, respectively. 
Thrombin-evoked $\mathrm{Ca}^{2+}$ release and entry were significantly reduced in the presence of TPEN. TPEN has been shown to cause a rapid decrease in $\left[\mathrm{Ca}^{2+}\right]_{\mathrm{s}}[40]$, where $\mathrm{Ca}^{2+}$ concentration is elevated ( 0.2-1 mM [41]), which might explain the significant reduction of the extent of $\mathrm{Ca}^{2+}$ release induced thrombin. The inhibitory effect of TPEN on $\mathrm{Ca}^{2+}$ entry mediated by thrombin might be partially attributed to its chelating effects and to the known activation of $\mathrm{Ca}^{2+}$ extrusion through the $\mathrm{Na}^{+} / \mathrm{Ca}^{2+}$ exchanger [42].

CCE has been shown to require a dynamic interplay between the ER $\mathrm{Ca}^{2+}$ sensor STIM1 and the PM channels Orai1 and hTRPC1 [7]. In human platelets we have recently reported that Orai1 mediates the communication between STIM1 and hTRPC1, which is essential to confer hTRPC1 properties of capacitative $\mathrm{Ca}^{2+}$ entry channel [8]. Here we present for the first time evidence for the interaction between endogenously expressed hTRPC6 and both Orai1 and STIM1 in platelets. The association between these proteins was detected in resting platelets and enhanced by the physiological agonist thrombin or extensive store depletion using TG + Iono. The interaction between hTRPC6 and both Orai1 and STIM1 was found to be independent on extracellular $\mathrm{Ca}^{2+}$ and might mediate the involvement of hTRPC6 in CCE in these cells.

On the basis that hTRPC6 and hTRPC3 have been shown to be involved in NCCE and that both channels have been reported to be associated to the same platelet membrane regions [43], we have explored the interaction between both proteins upon stimulation with thrombin or TG + Iono and OAG, a DAG analogue that activates NCCE [4]. Platelet treatment with thrombin or TG + Iono enhances interaction between hTRPC6 and hTRPC3 only when rises in $\left[\mathrm{Ca}^{2+}\right]_{\mathrm{c}}$ are allowed, a response that was abolished by cell loading with dimethyl-BAPTA. Since capacitative $\mathrm{Ca}^{2+}$ entry was first proposed as a mechanism for $\mathrm{Ca}^{2+}$ influx regulated by the $\mathrm{Ca}^{2+}$ content of the intracellular stores rather than by the $\mathrm{Ca}^{2+}$ signals generated by agonists [35], our findings suggest that this interaction is non-capacitative in nature due to its dependence on rises in $\left[\mathrm{Ca}^{2+}\right]_{\mathrm{c}}$. Similarly, stimulation with OAG increases the association of hTRPC6 with hTRPC3 when $\mathrm{Ca}^{2+}$ entry is allowed, suggesting that this interaction is $\mathrm{Ca}^{2+}$ dependent. In addition, this finding suggests that a different mechanism mediates the initial $\mathrm{Ca}^{2+}$ entry step activated by OAG. Interestingly, treatment with OAG decreased the interaction of hTRPC6 with Orai1 and STIM1, which indicates that activation of NCCE pathways results in displacement of hTRPC6 from the CCE protein complex to the NCCE mechanism. To further support in role of hTRPC3 in NCCE we have found that store depletion with TG + Iono did not induce association between hTRPC3 with hTRPC1, STIM1 or Orai1.

Our findings suggest that hTRPC6 interacts with the CCE channel protein Orai1 and the ER $\mathrm{Ca}^{2+}$ sensor STIM1 upon stimulation with the physiological agonist thrombin or extensive $\mathrm{Ca}^{2+}$ store depletion. hTRPC6 is required for CCE induced either by TG [4] or TPEN, which induces a decrease in $\left[\mathrm{Ca}^{2+}\right]_{\mathrm{S}}$ but avoiding rises in $\left[\mathrm{Ca}^{2+}\right]_{\mathrm{c}}$. The NCCE activator OAG displaces hTRPC6 from Orai1 and STIM1 and induces its association with hTRPC3. We propose that depletion of $\left[\mathrm{Ca}^{2+}\right]_{\mathrm{s}}$ induces the formation of a macromolecular complex involving plasma membrane $\mathrm{Ca}^{2+}$-permeable channels like Orai1, hTRPC6 and hTRPC1 [8]. In contrast, activation of NCCE results in displacement of hTRPC6 from the CCE pathway and favors $\mathrm{Ca}^{2+}$-dependent association between hTRPC6 and hTRPC3 (a schematic diagram of the proposed model is depicted in Figure 7). These data support that hTRPC6 participates in CCE and NCCE pathways in human platelets by association to different $\mathrm{Ca}^{2+}$-handling proteins. 


\section{ACKNOWLEDGEMENTS}

This work was supported by MEC grant BFU2007-60104. I.J. was supported by a MEC fellowship (BFU2007-60104).

\section{FOOTNOTES}

The abbreviations used are: $\left[\mathrm{Ca}^{2+}\right]_{c}$, cytosolic free calcium concentration; $\left[\mathrm{Ca}^{2+}\right]_{\mathrm{s}}$, free $\mathrm{Ca}^{2+}$ concentration in the intracellular stores; BSA, bovine serum albumin; CCE, capacitative $\mathrm{Ca}^{2+}$ entry; DAG, diacylglycerol; ER, endoplasmic reticulum; HBS, HEPES-buffered saline; hTRPC6, human canonical TRP6; Iono, ionomycin; $\mathrm{IP}_{3} \mathrm{R}$, inositol 1,4,5-trisphosphate receptor; NCCE, non-capacitative $\mathrm{Ca}^{2+}$ entry; OAG, 1-oleoyl-2-acetyl-sn-glycerol; PBS, phosphate-buffered saline; PLC, phospholipase C; PM, plasma membrane; PMSF, phenyl methyl sulphonyl fluoride; STIM1, stromal interaction molecule 1; TBST, tris-buffered saline with $0.1 \%$ Tween 20; TG, thapsigargin; TPEN, N,N,N',N'-tetrakis (2-pyridylmethyl) ethylene diamine; TRP, transient receptor potential. 


\section{REFERENCES}

1 Montell, C. (2003) The venerable inveterate invertebrate TRP channels. Cell Calcium. 33, 409-417

2 Cheng, K. T., Liu, X., Ong, H. L. and Ambudkar, I. S. (2008) Functional requirement for Orai1 in store-operated TRPC1-STIM1 channels. J Biol Chem. 283, 12935-12940

3 Liao, Y., Erxleben, C., Abramowitz, J., Flockerzi, V., Zhu, M. X., Armstrong, D. L. and Birnbaumer, L. (2008) Functional interactions among Orai1, TRPCs, and STIM1 suggest a STIM-regulated heteromeric Orai/TRPC model for SOCE/Icrac channels. Proc Natl Acad Sci U S A. 105, 2895-2900

4 Jardin, I., Redondo, P. C., Salido, G. M. and Rosado, J. A. (2008) Phosphatidylinositol 4,5-bisphosphate enhances store-operated calcium entry through hTRPC6 channel in human platelets. Biochim Biophys Acta. 1783, 84-97

5 Vazquez, G., Wedel, B. J., Kawasaki, B. T., Bird, G. S. and Putney, J. W., Jr. (2004) Obligatory role of Src kinase in the signaling mechanism for TRPC3 cation channels. J Biol Chem. 279, 40521-40528

6 Vig, M., Peinelt, C., Beck, A., Koomoa, D. L., Rabah, D., Koblan-Huberson, M., Kraft, S., Turner, H., Fleig, A., Penner, R. and Kinet, J. P. (2006) CRACM1 is a plasma membrane protein essential for store-operated $\mathrm{Ca}^{2+}$ entry. Science. 312, 1220-1223

7 Ong, H. L., Cheng, K. T., Liu, X., Bandyopadhyay, B. C., Paria, B. C., Soboloff, J., Pani, B., Gwack, Y., Srikanth, S., Singh, B. B., Gill, D. L. and Ambudkar, I. S. (2007) Dynamic assembly of TRPC1-STIM1-Orai1 ternary complex is involved in store-operated calcium influx. Evidence for similarities in store-operated and calcium release-activated calcium channel components. J Biol Chem. 282, 9105-9116

8 Jardin, I., Lopez, J. J., Salido, G. M. and Rosado, J. A. (2008) Orai1 Mediates the Interaction between STIM1 and hTRPC1 and Regulates the Mode of Activation of hTRPC1forming $\mathrm{Ca}^{2+}$ Channels. J Biol Chem. 283, 25296-25304

9 Roos, J., DiGregorio, P. J., Yeromin, A. V., Ohlsen, K., Lioudyno, M., Zhang, S., Safrina, O., Kozak, J. A., Wagner, S. L., Cahalan, M. D., Velicelebi, G. and Stauderman, K. A. (2005) STIM1, an essential and conserved component of store-operated $\mathrm{Ca}^{2+}$ channel function. J Cell Biol. 169, 435-445

10 Mercer, J. C., Dehaven, W. I., Smyth, J. T., Wedel, B., Boyles, R. R., Bird, G. S. and Putney, J. W., Jr. (2006) Large store-operated calcium selective currents due to coexpression of Orai1 or Orai2 with the intracellular calcium sensor, Stim1. J Biol Chem. 281, 24979-24990

11 Thebault, S., Zholos, A., Enfissi, A., Slomianny, C., Dewailly, E., Roudbaraki, M., Parys, J. and Prevarskaya, N. (2005) Receptor-operated $\mathrm{Ca}^{2+}$ entry mediated by TRPC3/TRPC6 proteins in rat prostate smooth muscle (PS1) cell line. J Cell Physiol. 204, 320-328

12 Hassock, S. R., Zhu, M. X., Trost, C., Flockerzi, V. and Authi, K. S. (2002) Expression and role of TRPC proteins in human platelets: evidence that TRPC6 forms the store-independent calcium entry channel. Blood. 100, 2801-2811

13 Redondo, P. C., Jardin, I., Lopez, J. J., Salido, G. M. and Rosado, J. A. (2008) Intracellular $\mathrm{Ca}^{2+}$ store depletion induces the formation of macromolecular complexes involving hTRPC1, hTRPC6, the type II IP 3 receptor and SERCA3 in human platelets. Biochim Biophys Acta. 1783, 1163-1176 
14 Wang, Y., Deng, X., Hewavitharana, T., Soboloff, J. and Gill, D. L. (2008) Stim, orai and trpc channels in the control of calcium entry signals in smooth muscle. Clin Exp Pharmacol Physiol. 35, 1127-1133

15 Parekh, A. B. and Putney, J. W., Jr. (2005) Store-operated calcium channels. Physiol Rev. 85, 757-810

16 Liao, Y., Erxleben, C., Yildirim, E., Abramowitz, J., Armstrong, D. L. and Birnbaumer, L. (2007) Orai proteins interact with TRPC channels and confer responsiveness to store depletion. Proc Natl Acad Sci U S A. 104, 4682-4687

17 Redondo, P. C., Jardin, I., Hernandez-Cruz, J. M., Pariente, J. A., Salido, G. M. and Rosado, J. A. (2005) Hydrogen peroxide and peroxynitrite enhance $\mathrm{Ca}^{2+}$ mobilization and aggregation in platelets from type 2 diabetic patients. Biochem Biophys Res Commun. 333, 794-802

18 Grynkiewicz, G., Poenie, M. and Tsien, R. Y. (1985) A new generation of $\mathrm{Ca}^{2+}$ indicators with greatly improved fluorescence properties. J Biol Chem. 260, 3440-3450

19 Redondo, P. C., Harper, M. T., Rosado, J. A. and Sage, S. O. (2006) A role for cofilin in the activation of store-operated calcium entry by de novo conformational coupling in human platelets. Blood. 107, 973-979

20 Watson, S. P. and Authi, K. S. (1996) Platelets : a practical approach. IRL Press at Oxford University Press, Oxford

21 Woodard, G. E., Salido, G. M. and Rosado, J. A. (2008) Enhanced exocytotic-like insertion of Orai1 into the plasma membrane upon intracellular $\mathrm{Ca}^{2+}$ store depletion. Am J Physiol Cell Physiol. 294, C1323-1331

22 Rosado, J. A., Lopez, J. J., Harper, A. G., Harper, M. T., Redondo, P. C., Pariente, J. A., Sage, S. O. and Salido, G. M. (2004) Two pathways for store-mediated calcium entry differentially dependent on the actin cytoskeleton in human platelets. J Biol Chem. 279, 29231-29235

23 Manji, S. S., Parker, N. J., Williams, R. T., van Stekelenburg, L., Pearson, R. B., Dziadek, M. and Smith, P. J. (2000) STIM1: a novel phosphoprotein located at the cell surface. Biochim Biophys Acta. 1481, 147-155

24 Gwack, Y., Srikanth, S., Feske, S., Cruz-Guilloty, F., Oh-hora, M., Neems, D. S., Hogan, P. G. and Rao, A. (2007) Biochemical and functional characterization of Orai proteins. J Biol Chem. 282, 16232-16243

25 Zhang, W., Chu, X., Tong, Q., Cheung, J. Y., Conrad, K., Masker, K. and Miller, B. A. (2003) A novel TRPM2 isoform inhibits calcium influx and susceptibility to cell death. J Biol Chem. 278, 16222-16229

26 Redondo, P. C., Salido, G. M., Pariente, J. A., Sage, S. O. and Rosado, J. A. (2008) SERCA2b and 3 play a regulatory role in store-operated calcium entry in human platelets. Cell Signal. 20, 337-346

27 Hofer, A. M., Fasolato, C. and Pozzan, T. (1998) Capacitative Ca2+ entry is closely linked to the filling state of internal $\mathrm{Ca}^{2+}$ stores: a study using simultaneous measurements of ICRAC and intraluminal [Ca2+]. J Cell Biol. 140, 325-334

28 Iwasaki, H., Mori, Y., Hara, Y., Uchida, K., Zhou, H. and Mikoshiba, K. (2001) 2Aminoethoxydiphenyl borate (2-APB) inhibits capacitative calcium entry independently of the function of inositol 1,4,5-trisphosphate receptors. Receptors Channels. 7, 429-439

29 Brenner, J. S. and Dolmetsch, R. E. (2007) TrpC3 regulates hypertrophy-associated gene expression without affecting myocyte beating or cell size. PLoS ONE. 2, e802

30 Jardin, I., Lopez, J. J., Salido, G. M. and Rosado, J. A. (2008) Orai1 mediates the interaction between STIM1 and hTRPC1 and regulates the mode of activation of hTRPC1forming $\mathrm{Ca}^{2+}$ channels. J Biol Chem 
$31 \mathrm{Xu}, \mathrm{S}$. Z. and Beech, D. J. (2001) TrpC1 is a membrane-spanning subunit of storeoperated $\mathrm{Ca}(2+)$ channels in native vascular smooth muscle cells. Circ Res. 88, 84-87

32 Rosado, J. A., Brownlow, S. L. and Sage, S. O. (2002) Endogenously expressed Trp1 is involved in store-mediated $\mathrm{Ca}^{2+}$ entry by conformational coupling in human platelets. $\mathrm{J}$ Biol Chem. 277, 42157-42163

33 Boulay, G., Zhu, X., Peyton, M., Jiang, M., Hurst, R., Stefani, E. and Birnbaumer, L. (1997) Cloning and expression of a novel mammalian homolog of Drosophila transient receptor potential (Trp) involved in calcium entry secondary to activation of receptors coupled by the Gq class of G protein. J Biol Chem. 272, 29672-29680

34 Trebak, M., Vazquez, G., Bird, G. S. and Putney, J. W., Jr. (2003) The TRPC3/6/7 subfamily of cation channels. Cell Calcium. 33, 451-461

35 Putney, J. W., Jr. (1986) A model for receptor-regulated calcium entry. Cell Calcium. 7, $1-12$

36 Kiselyov, K., Xu, X., Mozhayeva, G., Kuo, T., Pessah, I., Mignery, G., Zhu, X., Birnbaumer, L. and Muallem, S. (1998) Functional interaction between InsP3 receptors and store-operated Htrp3 channels. Nature. 396, 478-482

37 Vazquez, G., Lievremont, J. P., St, J. B. G. and Putney, J. W., Jr. (2001) Human Trp3 forms both inositol trisphosphate receptor-dependent and receptor-independent storeoperated cation channels in DT40 avian B lymphocytes. Proc Natl Acad Sci U S A. 98, 11777-11782

38 Zitt, C., Obukhov, A. G., Strubing, C., Zobel, A., Kalkbrenner, F., Luckhoff, A. and Schultz, G. (1997) Expression of TRPC3 in Chinese hamster ovary cells results in calciumactivated cation currents not related to store depletion. J Cell Biol. 138, 1333-1341

39 Zhu, X., Jiang, M. and Birnbaumer, L. (1998) Receptor-activated Ca2+ influx via human Trp3 stably expressed in human embryonic kidney (HEK)293 cells. Evidence for a non-capacitative $\mathrm{Ca}^{2+}$ entry. J Biol Chem. 273, 133-142

40 Caroppo, R., Colella, M., Colasuonno, A., DeLuisi, A., Debellis, L., Curci, S. and Hofer, A. M. (2003) A reassessment of the effects of luminal $\left[\mathrm{Ca}^{2+}\right]$ on inositol 1,4,5trisphosphate-induced $\mathrm{Ca}^{2+}$ release from internal stores. J Biol Chem. 278, 39503-39508

41 Verkhratsky, A. (2005) Physiology and pathophysiology of the calcium store in the endoplasmic reticulum of neurons. Physiol Rev. 85, 201-279

42 Shmist, Y. A., Kamburg, R., Ophir, G., Kozak, A., Shneyvays, V., Appelbaum, Y. J. and Shainberg, A. (2005) N,N,N',N'-tetrakis(2-pyridylmethyl)-ethylenediamine improves myocardial protection against ischemia by modulation of intracellular $\mathrm{Ca}^{2+}$ homeostasis. $\mathrm{J}$ Pharmacol Exp Ther. 313, 1046-1057

43 Brownlow, S. L. and Sage, S. O. (2005) Transient receptor potential protein subunit assembly and membrane distribution in human platelets. Thromb Haemost. 94, 839-845 


\section{FIGURE LEGENDS}

Figure 1. Time-course of thrombin-induced hTRPC6 co-immunoprecipitation with STIM1 and Orai1 in human platelets.

A-D, Human platelets $\left(2 \times 10^{9} \mathrm{cell} / \mathrm{mL}\right)$ were suspended in a $\mathrm{Ca}^{2+}$-free medium $(100 \mu \mathrm{M}$ EGTA added) and then stimulated for various periods of time (10-60 s) with thrombin (1 $\mathrm{U} / \mathrm{mL}$ ) and lysed. Whole cell lysates were immunoprecipitated (IP) with anti-hTRPC6 (A and $\mathbf{B})$, anti-STIM1 (C) or anti-Orai1 antibody (D). Immunoprecipitates were subjected to $10 \%$ SDS-PAGE and subsequent Western blotting with a specific anti-STIM1 (A), antiOrai1 (B) or anti-hTRPC6 antibody (C and D). Membranes were reprobed with the antibody used for immunoprecipitation for protein loading control. The panel shows results from one experiment representative of 5 others. Molecular masses indicated on the right were determined using molecular-mass markers run in the same gel. Histograms represent the quantification of hTRPC6-STIM1 association (A) or hTRPC6-Orai1 association (B) in resting (control) and thrombin-treated cells. Results are presented as arbitrary optical density units and expressed as mean \pm S.E.M. $* P<0.05$ vs. control.

Figure 2. Time-course of TG + ionomycin-induced hTRPC6 co-immunoprecipitation with STIM1 and Orai1 in human platelets.

Human platelets $\left(2 \times 10^{9}\right.$ cell $\left./ \mathrm{mL}\right)$ were suspended in a $\mathrm{Ca}^{2+}$-free medium $(100 \mu \mathrm{M}$ EGTA added) and then stimulated for various periods of time (10-60 s) with TG $(1 \mu \mathrm{M})+$ Iono (50 $\mathrm{nM}$ ) and lysed. Whole cell lysates were immunoprecipitated (IP) with anti-hTRPC6 (A and B), anti-STIM1 (C) or anti-Orai1 antibody (D) and immunoprecipitates were subjected to 10 $\%$ SDS-PAGE and subsequent Western blotting with a specific anti-STIM1 (A) anti-Orai1 (B) or anti-hTRPC6 antibody (C and D). Membranes were reprobed with the antibody used for immunoprecipitation for protein loading control. The panel shows results from one experiment representative of 5 others. Molecular masses indicated on the right were determined using molecular-mass markers run in the same gel. Histograms represent the quantification of hTRPC6-STIM1 association (A) or hTRPC6-Orai1 association (B) in resting (control) and thrombin-treated cells. Results are presented as arbitrary optical density units and expressed as mean \pm S.E.M. $* P<0.05$ vs. control.

Figure 3. TPEN-mediated $\mathrm{Ca}^{2+}$ entry is attenuated by electroporation of the antihTRPC6 antibody.

(A) Fura-2-loaded human platelets were suspended in a $\mathrm{Ca}^{2+}$-free medium (100 $\mu \mathrm{M}$ EGTA was added) and treated with TPEN (500 $\mathrm{MM}$; upper graph) or the vehicle (DMSO, lower graph), as control. Platelets were stimulated with $1 \mathrm{U} / \mathrm{mL}$ thrombin (upper graph) or the vehicle (HBS, lower graph) 1 min later followed by the addition of $\mathrm{CaCl}_{2}$ (final concentration $300 \mu \mathrm{M}$ ) $3 \mathrm{~min}$ later to initiate $\mathrm{Ca}^{2+}$ entry. (B) Human platelets were electropermeabilized in a Gene Pulser as described in "material and methods" and then were incubated in the presence of $1 \mu \mathrm{g} / \mathrm{mL}$ anti-hTRPC6 antibody, anti-hTRPC3 antibody, both or $1 \mu \mathrm{g} / \mathrm{mL}$ rabbit or goat IgG (Control upper graph and lower graph) for $60 \mathrm{~min}$ as indicated. Cells were then stimulated in a $\mathrm{Ca}^{2+}$-free medium $(250 \mu \mathrm{M}$ EGTA was required since electroporated cells were suspended in medium containing $200 \mu \mathrm{M} \mathrm{CaCl}_{2}$, see material and 
methods) with $500 \mu \mathrm{M}$ TPEN (upper graph) or the vehicle (DMSO, lower graph) and 3 min later $\mathrm{CaCl}_{2}(1 \mathrm{mM})$ was added to the medium to initiate $\mathrm{Ca}^{2+}$ entry. The traces are representative of five independent experiments.

\section{Figure 4. Thrombin and extensive $\mathrm{Ca}^{2+}$ store depletion induced by $\mathrm{TG}+$ ionomycin induce $\mathrm{Ca}^{2+}$-dependent co-immunoprecipitation of hTRPC6 with hTRPC3.}

Control (A and $\mathbf{B})$ and dimethyl BAPTA-loaded $(\mathbf{E}$ and $\mathbf{F})$ human platelets $\left(2 \times 10^{9} \mathrm{cell} / \mathrm{mL}\right)$ were suspended in a $\mathrm{Ca}^{2+}$-free medium $(100 \mu \mathrm{M}$ EGTA added) and then stimulated for $30 \mathrm{~s}$ with thrombin (1U/mL; A and E) or TG $(1 \mu \mathrm{M})+$ Iono $(50 \mathrm{nM}$; $\mathbf{B}$ and F) and lysed. Whole cell lysates were immunoprecipitated (IP) with anti-hTRPC6 antibody (A, B, E and F upper panels) or anti-hTRPC3 antibody (A, B, E and F lower panels) and immunoprecipitates were subjected to $10 \%$ SDS-PAGE and subsequent Western blotting with a specific antihTRPC6 (upper panels) or anti-hTRPC3 (lower panels) antibody. Membranes were reprobed with the antibody used for immunoprecipitation for protein loading control. The panels show results from one experiment representative of 5 others. Molecular masses indicated on the right were determined using molecular-mass markers run in the same gel. Histograms represent the quantification of hTRPC6-hTRPC3 association in resting (control) and stimulated cells. Results are presented as arbitrary optical density units and expressed as mean \pm S.E.M. ${ }^{*} P<0.05$ vs. control. (C and D) Human platelets were incubated at $37{ }^{\circ} \mathrm{C}$ for $30 \mathrm{~min}$ in the presence or absence of $10 \mu \mathrm{M}$ dimethyl BAPTA, as indicated. At the time of experiment $100 \mu \mathrm{M}$ EGTA was added. Cells were then stimulated with $1 \mathrm{U} / \mathrm{mL}$ thrombin (C) or $1 \mu \mathrm{M}$ TG $+50 \mathrm{nM}$ Iono (D). Elevations in $\left[\mathrm{Ca}^{2+}\right]_{\mathrm{c}}$ were monitored using the 340/380 $\mathrm{nm}$ ratio as described in the materials and methods section. Traces shown are representative of 5 independent experiments.

Figure 5. OAG enhances co-immunoprecipitation of hTRPC6 with hTRPC3 in the presence of extracellular $\mathrm{Ca}^{2+}$.

A-D, Human platelets $\left(2 \times 10^{9}\right.$ cell $\left./ \mathrm{mL}\right)$ were suspended in a $\mathrm{Ca}^{2+}$-free medium $(100 \mu \mathrm{M}$ EGTA added; A-C) or in a medium containing $1 \mathrm{mM} \mathrm{CaCl}_{2}$ (D) and then stimulated for $30 \mathrm{~s}$ with OAG (100 $\mu \mathrm{M})$ and lysed. Whole cell lysates were immunoprecipitated (IP) with antihTRPC6 antibody and immunoprecipitates were subjected to $10 \%$ SDS-PAGE and subsequent Western blotting with a specific anti-hTRPC6 (A-D, upper panels), anti-Orai1 (A, lower panel), anti-STIM1 (B, lower panel) or anti-hTRPC3 antibody (C and D, lower panels). Membranes were reprobed with the antibody used for immunoprecipitation for protein loading control. The panel shows results from one experiment representative of 5 others. Molecular masses indicated on the right were determined using molecular-mass markers run in the same gel. Histograms represent the quantification of the association of hTRPC6 with Orai1 (A), STIM1 (B) and hTRPC3 (C and D) in resting (control) and OAGstimulated cells. Results are presented as arbitrary optical density units and expressed as mean \pm S.E.M. ${ }^{*} P<0.05$ vs. control. (E-H) Human platelets were electropermeabilized in a Gene Pulser as described in "material and methods" and then were incubated in the absence (E) or presence of $1 \mu \mathrm{g} / \mathrm{mL}$ anti-hTRPC6 antibody (G), anti-hTRPC3 antibody (H), or rabbit anti-mouse IgG (F) for $60 \mathrm{~min}$ as indicated. Platelets were suspended in a $\mathrm{Ca}^{2+}$-free medium (250 $\mu$ M EGTA was added) and stimulated with OAG (100 $\mu \mathrm{M}$; E upper graph, F, G and H) or the vehicle (DMSO; E lower graph), as control, followed by the addition of $\mathrm{CaCl}_{2}$ 
(final concentration $1 \mathrm{mM}$ ) 3 min later to initiate $\mathrm{Ca}^{2+}$ entry.

Figure 6. Treatment with TG + ionomycin is unable to induce co-immunoprecipitation of hTRPC3 with hTRPC1, STIM1 or Orai1.

Human platelets $\left(2 \times 10^{9}\right.$ cell $\left./ \mathrm{mL}\right)$ were suspended in a $\mathrm{Ca}^{2+}$-free medium $(100 \mu \mathrm{M}$ EGTA added) and then stimulated for $30 \mathrm{~s}$ with TG $(1 \mu \mathrm{M})+$ Iono $(50 \mathrm{nM})$ and lysed. Whole cell lysates were immunoprecipitated (IP) with anti-hTRPC3 (upper panels), anti-hTRPC1 (A, lower panel), anti-STIM1 (B, lower panel) or anti-Orai1 antibody (C, lower panel) and immunoprecipitates were subjected to $10 \%$ SDS-PAGE and subsequent Western blotting with a specific anti-hTRPC1 (A, upper panel), anti-STIM1 (B, upper panel), anti-Orai1 (C, upper panel) or anti-hTRPC3 antibody (lower panels). Membranes were reprobed with the antibody used for immunoprecipitation for protein loading control. The panel shows results from one experiment representative of 5 others. Molecular masses indicated on the right were determined using molecular-mass markers run in the same gel. Histograms (A) represent the quantification of the association of hTRPC1 with hTRPC3 in resting (control) and TG+Iono-stimulated cells. Results are presented as arbitrary optical density units and expressed as mean \pm S.E.M.

Figure 7. Speculative model of the involvement of hTRPC6 in capacitative and noncapacitative $\mathrm{Ca}^{2+}$ entry in platelets.

Activation of phospholipase C (PLC), via G protein-coupled receptors, results in the synthesis of $\mathrm{IP}_{3}$, which, in turn, activates $\mathrm{IP}_{3}$ receptors $\left(\mathrm{IP}_{3} \mathrm{R}\right)$ in the endoplasmic reticulum (ER). Depletion of the ER leads to the association of hTRPC6 to Orai1 and STIM1 (presented as the ER $\mathrm{Ca}^{2+}$ sensor) to participate in store-operated or capacitative $\mathrm{Ca}^{2+}$ entry (CCE). In contrast, activation of a non-capacitative $\mathrm{Ca}^{2+}$ entry (NCCE) pathway (i.e. via generation of DAG) displaces hTRPC6 from Orai1 and STIM1 and induces its association with hTRPC3. 
B Biochemical Journal Immediate Publication. Published on 05 Mar 2009 as manuscript BJ20082179

A
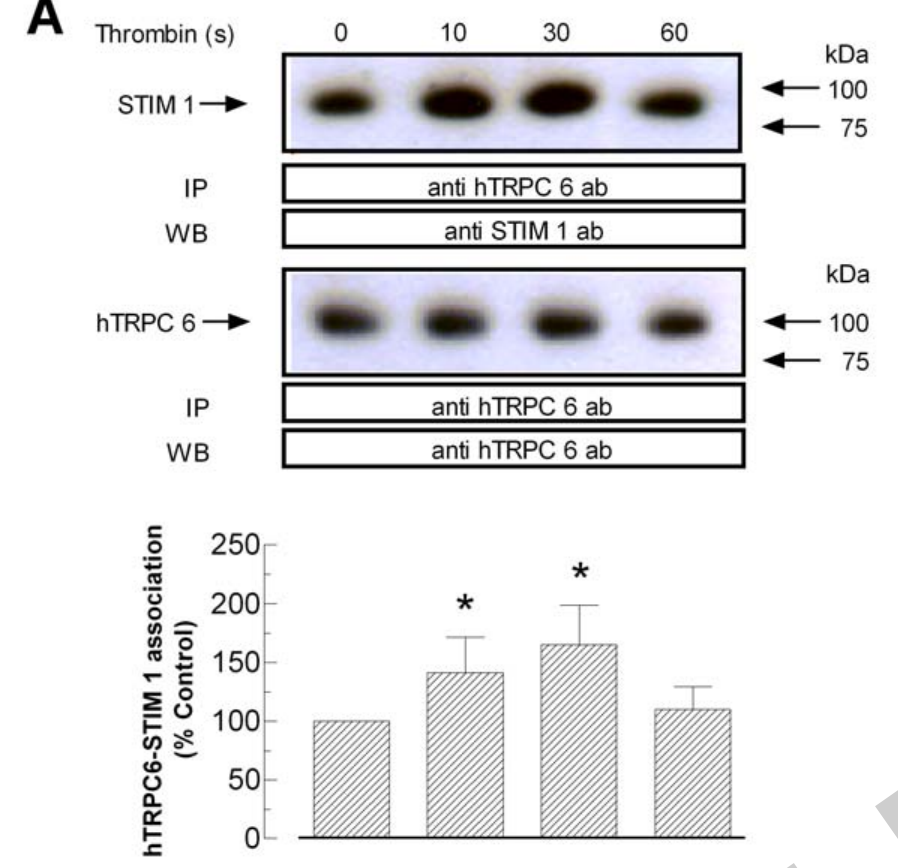

C

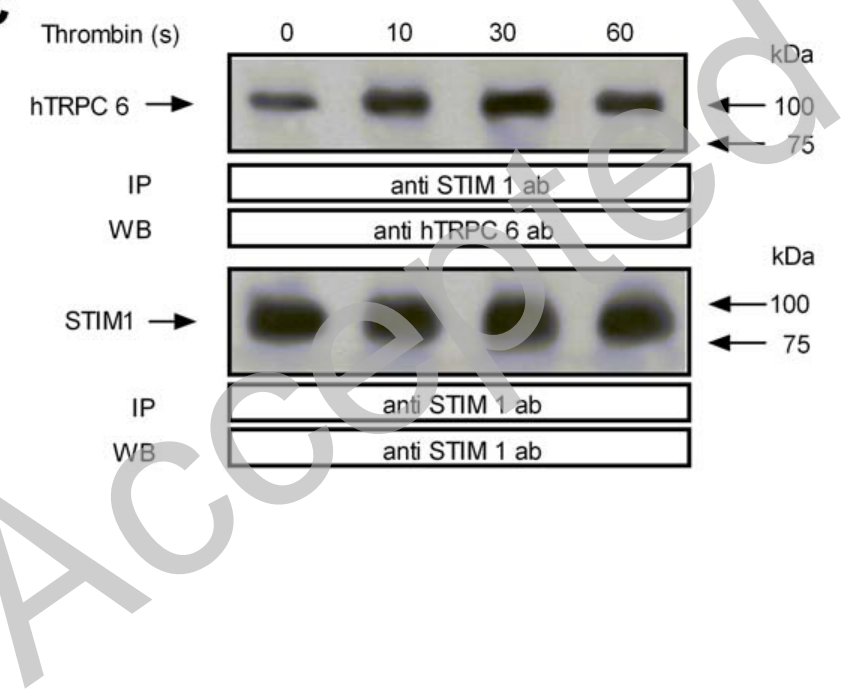

B $_{\text {T }}$

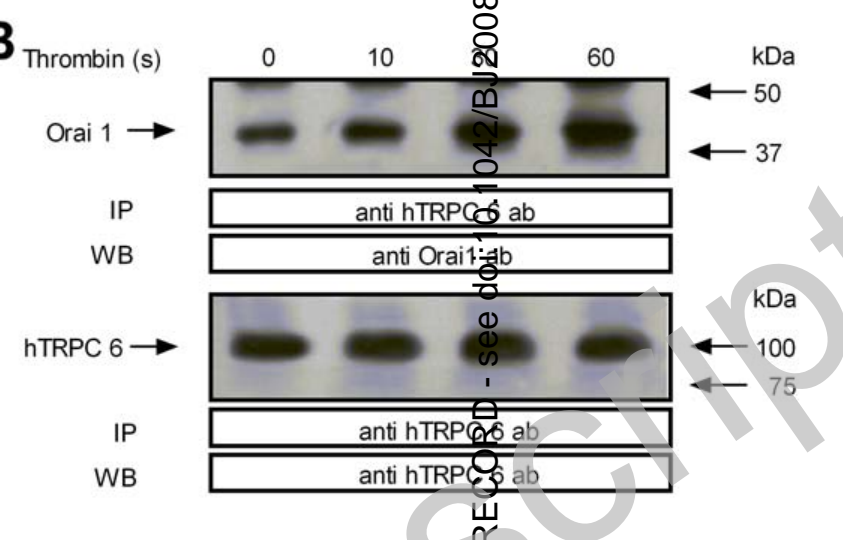

D

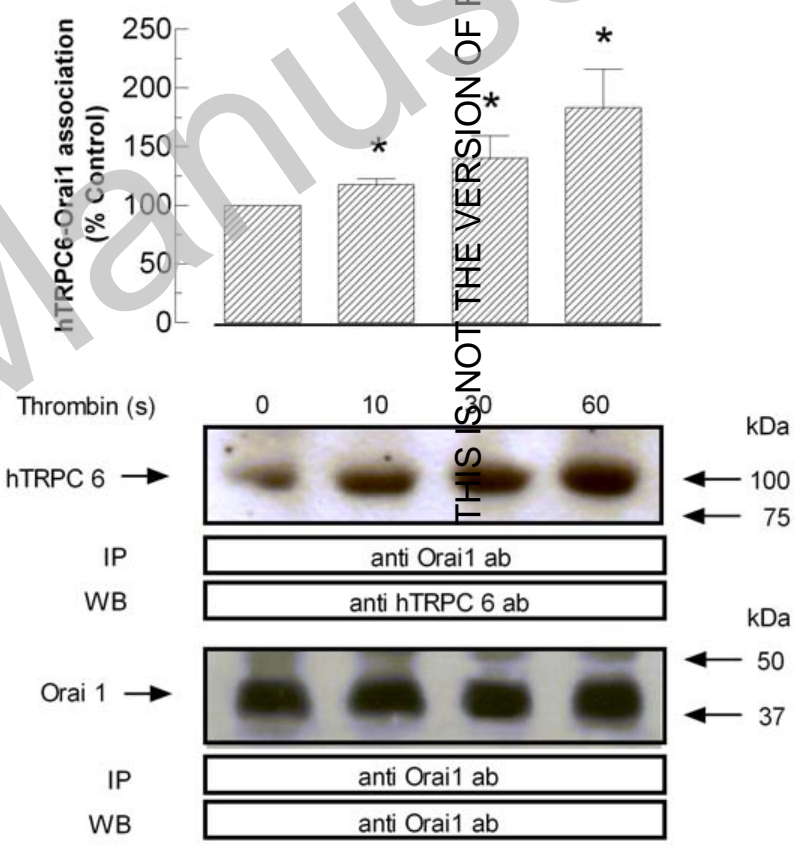

Licenced copy. Copying is not permitted, except with prior permission and as allowed by law. (C) 2009 The Authors Journal compilation ( 2009 Portland Press Limited 
A
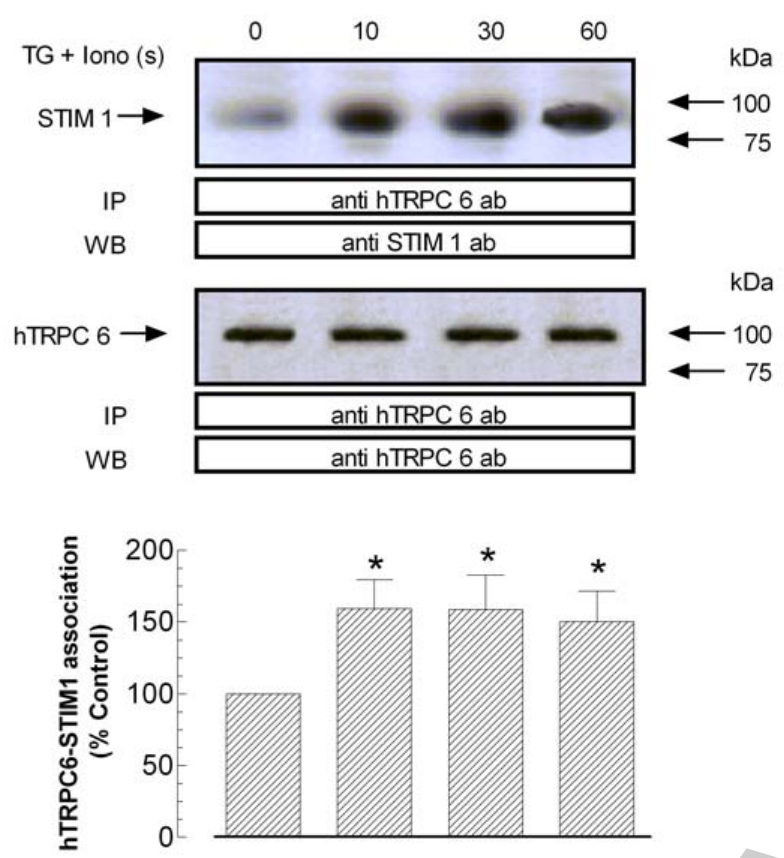

C

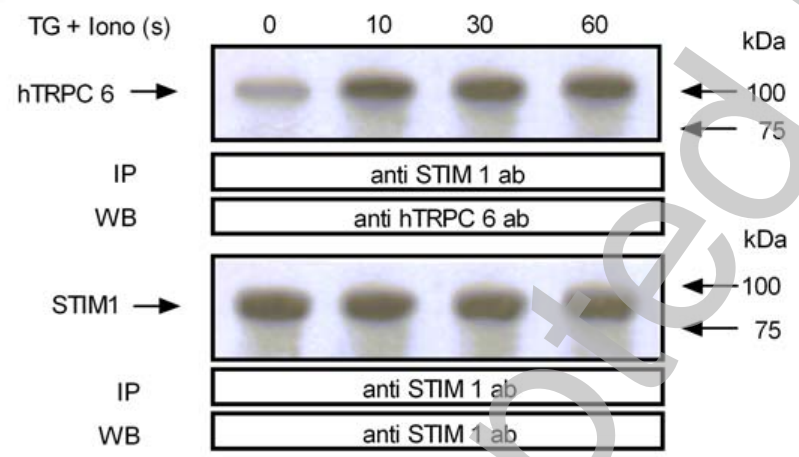

B
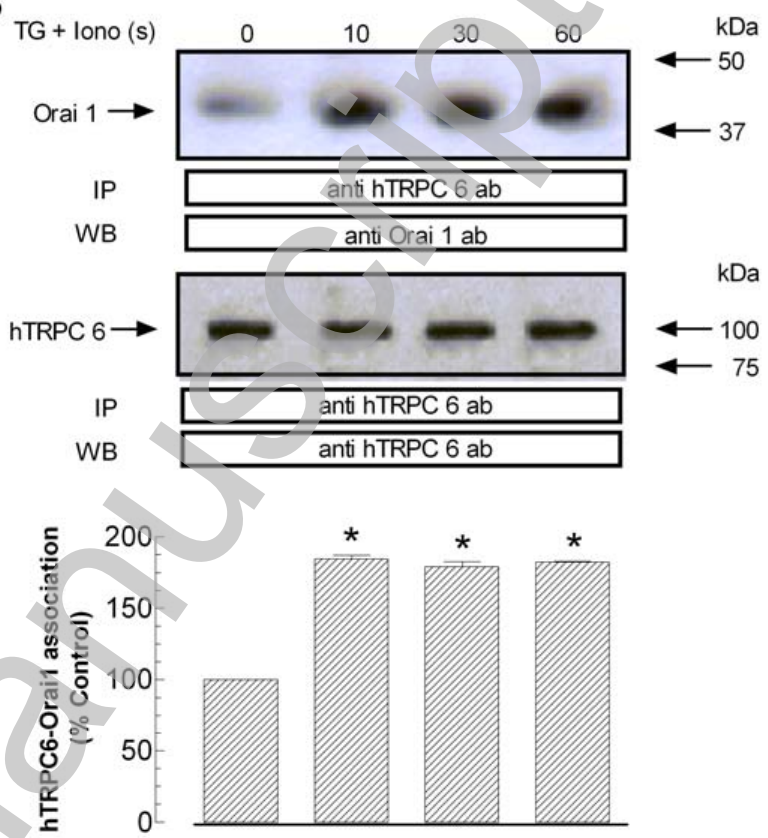

D

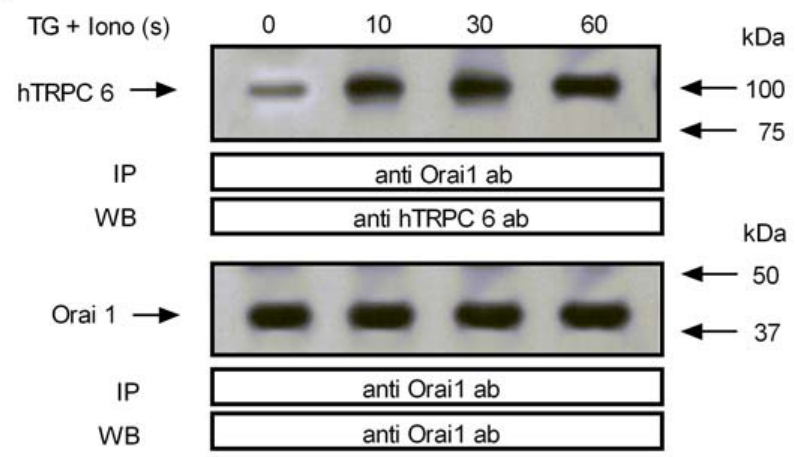



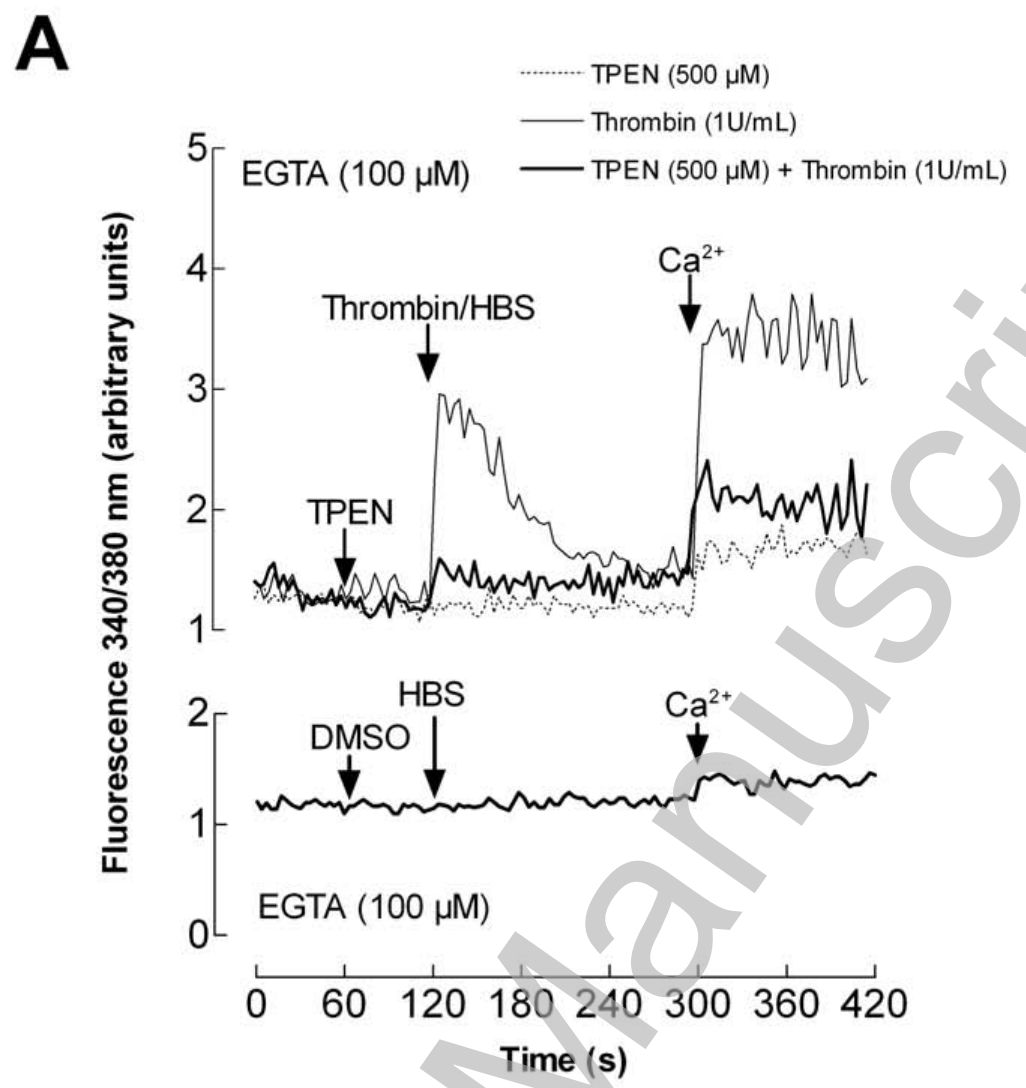

B

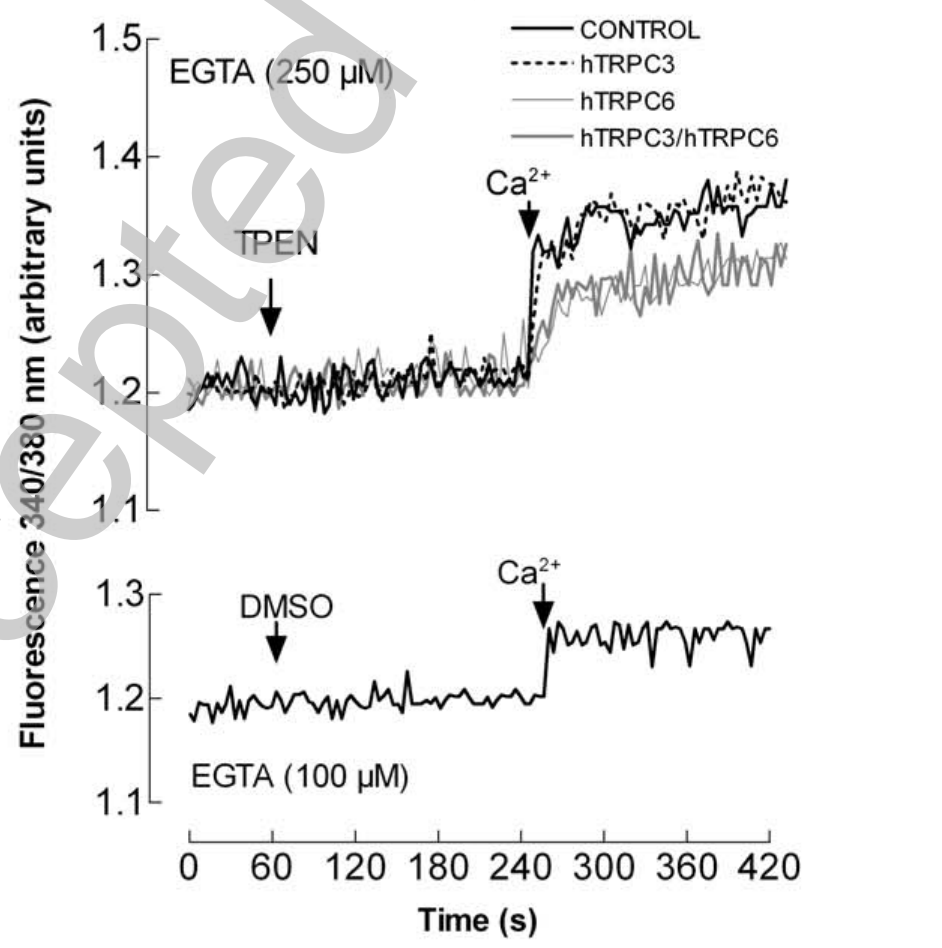




\section{B Biochemical Journal Immediate Publication. Published on 05 Mar 2009 as manuscript BJ20082179}

A

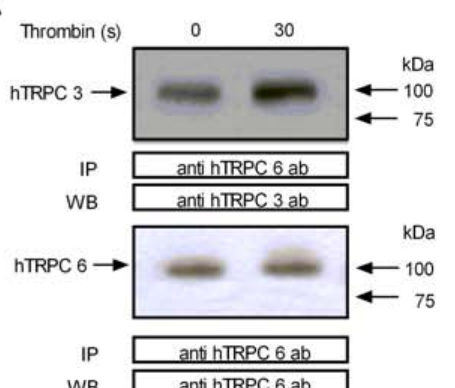

WB anthTRPC 6 ab
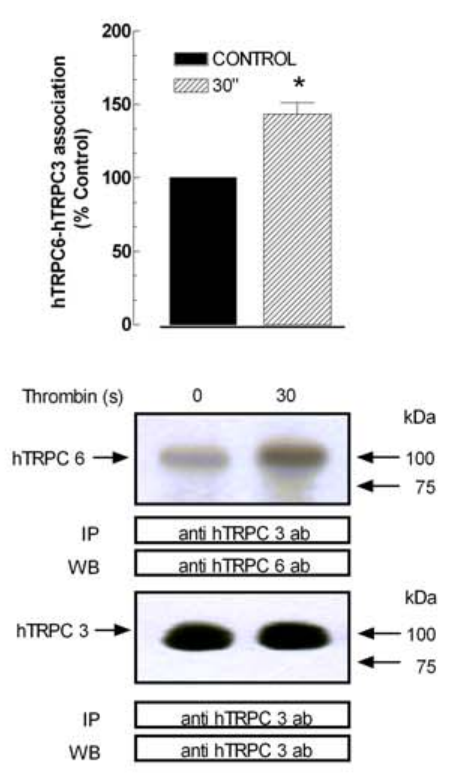

B
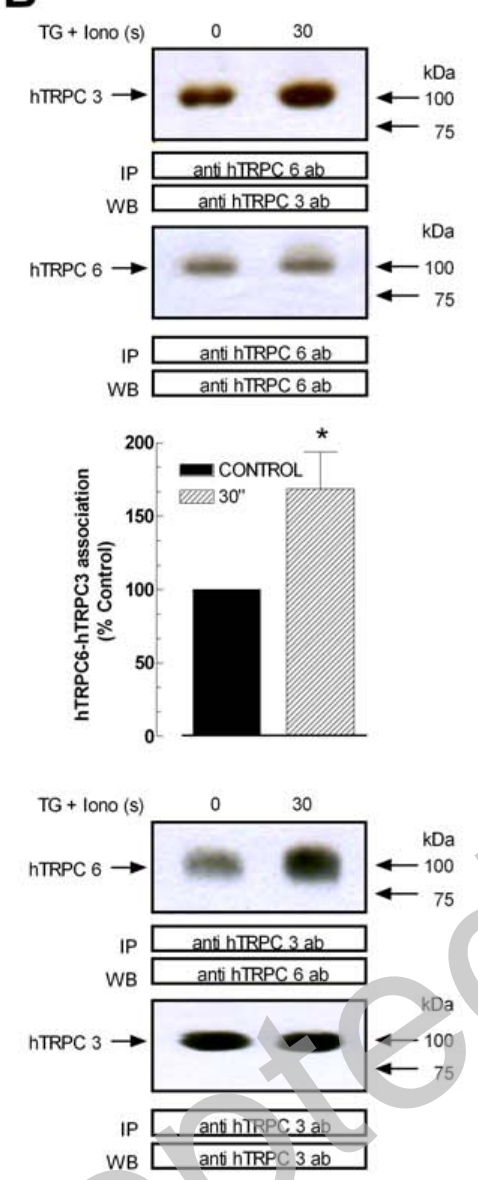

C

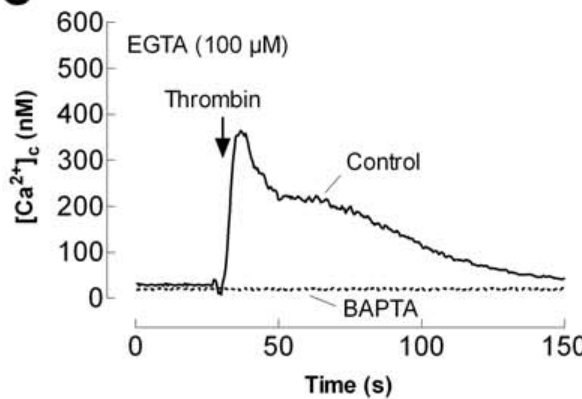

E
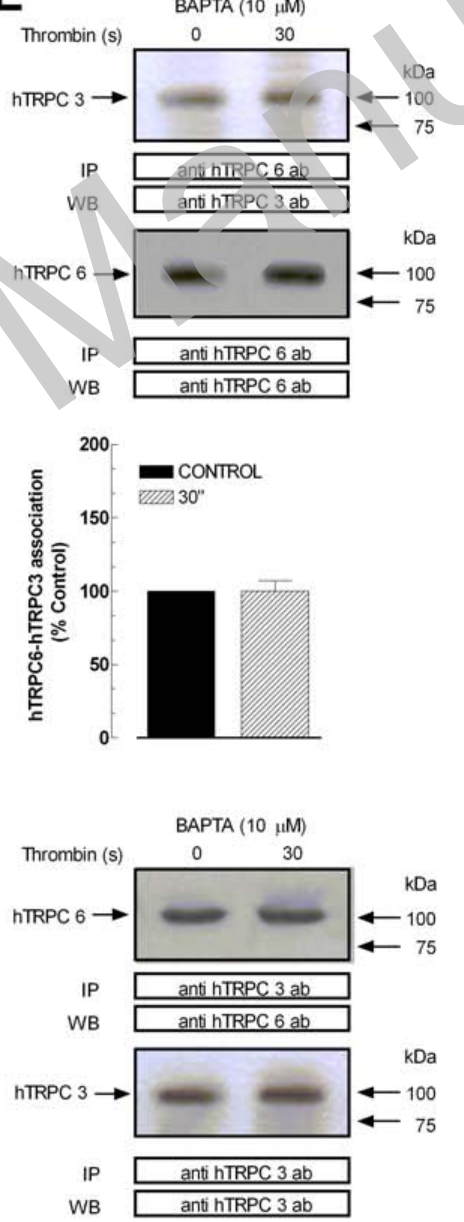

$\underset{\sim}{\sim} 500$ EGTA $(100 \mu \mathrm{M})$

₹ 400

워 300 这 200 $\Phi 100$

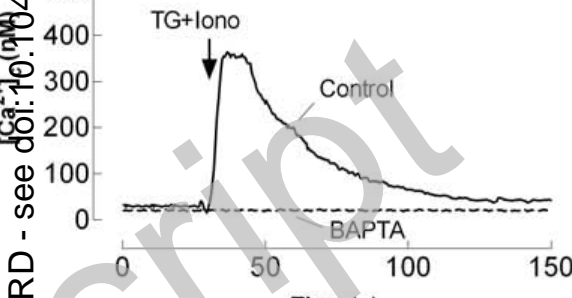

○

r

F

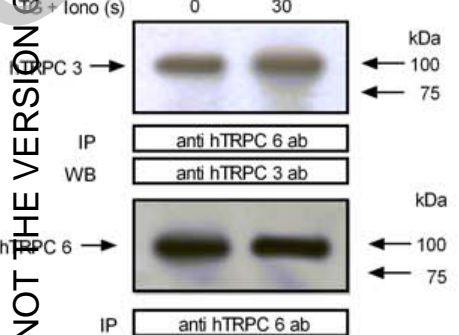

Z IP

$\mathcal{N}$ WB anthTRPC 6 ab

SO 200

焉

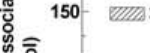

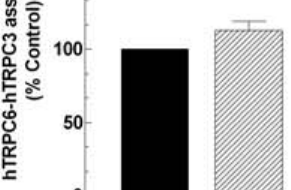

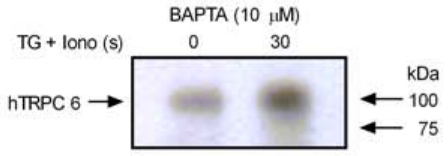

IP
WB
WanthiRPC 3 ab
antihTRPC 6 ab

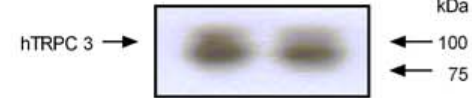

IP ant hTRPC 3 ab

Licenced copy. Copying is not permitted, except with prior permission and as allowed by law.

() 2009 The Authors Journal compilation @ 2009 Portland Press Limited 


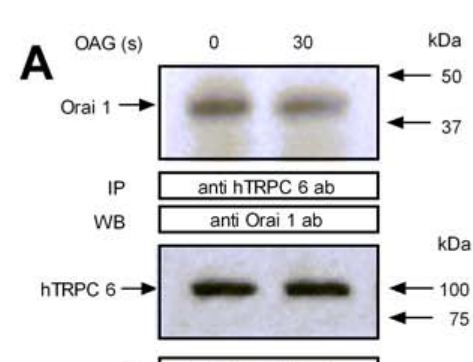

IP
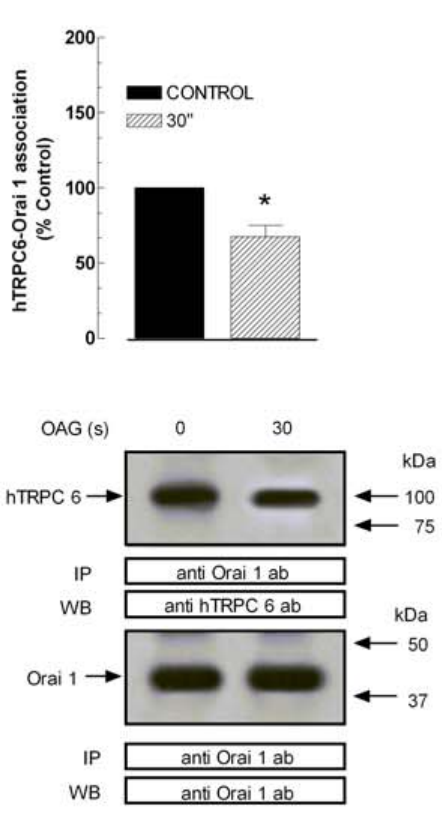

E

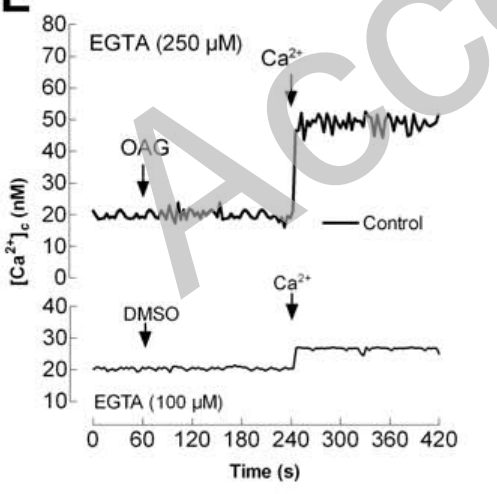

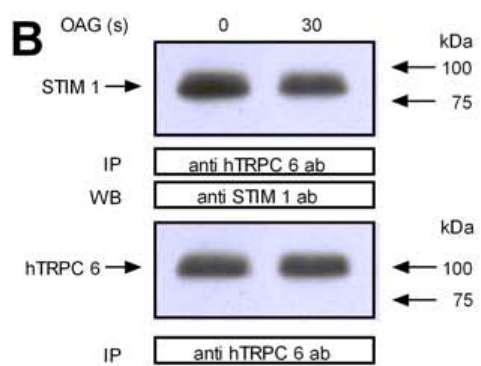

$\begin{array}{ll}\text { IP } \\ \text { WB } & \text { ant hTRPC 6 ab } \\ \text { antihTRPC 6 ab }\end{array}$
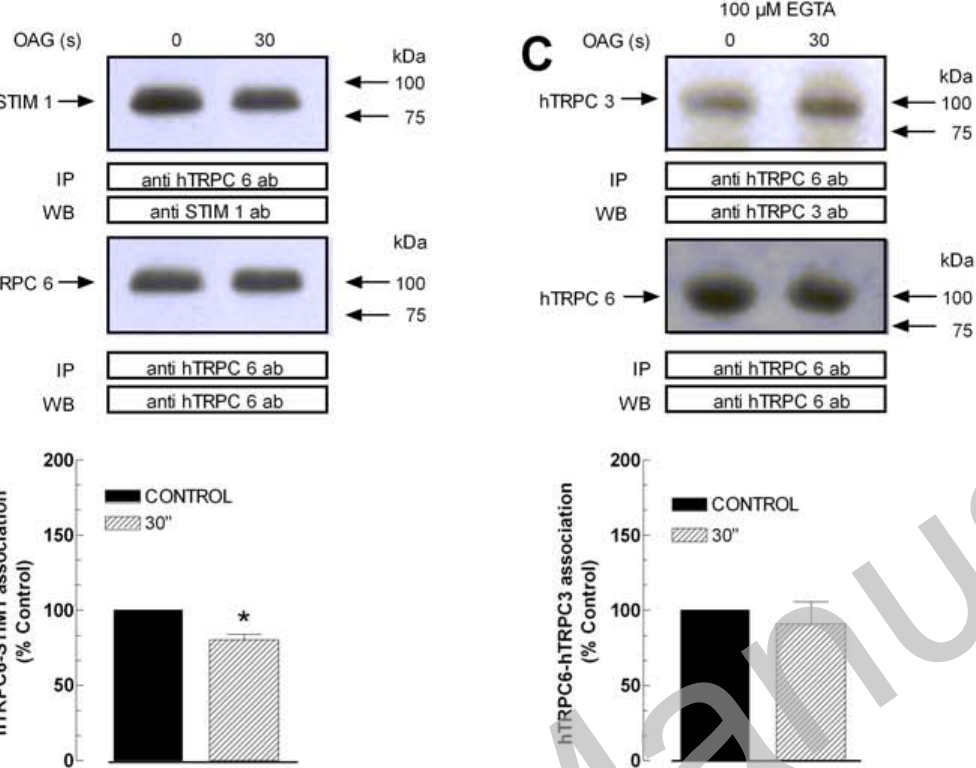

IP antihTRPC 6 ab
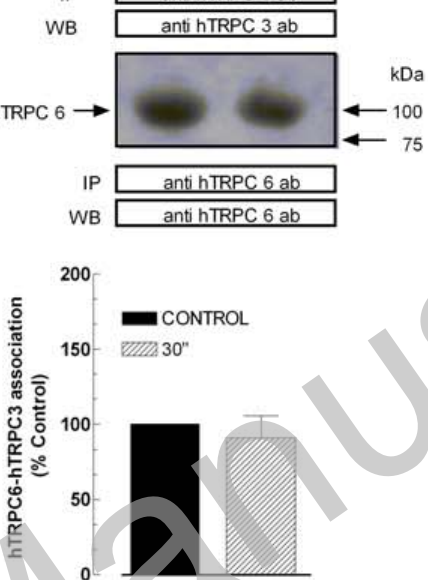

hTRPC $6 \rightarrow$

IP

WB antihTRC6ab

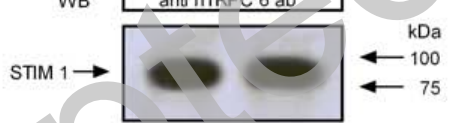

IP $\frac{\text { anti STIM 1 ab }}{\bar{C} \text { anti STIM 1 ab }}$

$\mathbf{F}$

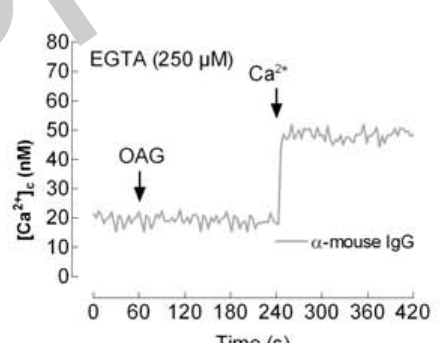
Time (s)

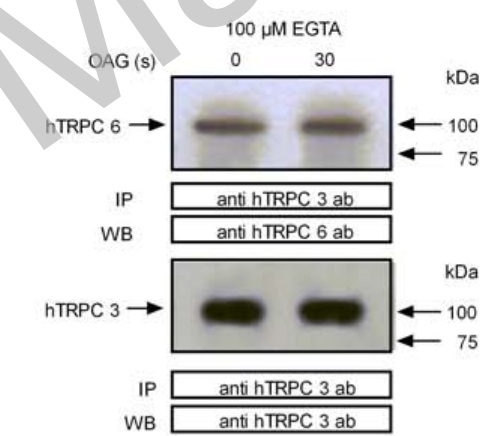

G

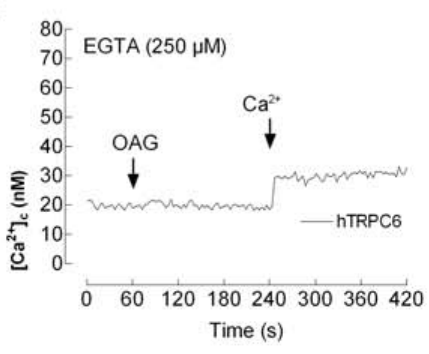

西 $1 \mathrm{mM} \mathrm{CaCl} I_{2}$

要

${ }_{0}^{1} \mathrm{mM} \mathrm{CaC}_{2}$

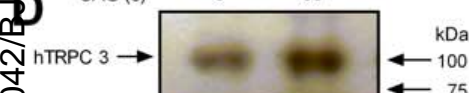

으

WB anth hTPC $3 \mathrm{ab}$

$\overline{0}$

$\underset{\Phi^{n T R P C} 6 \rightarrow \infty}{\square} \div 0$

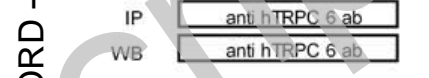

800

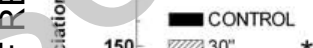

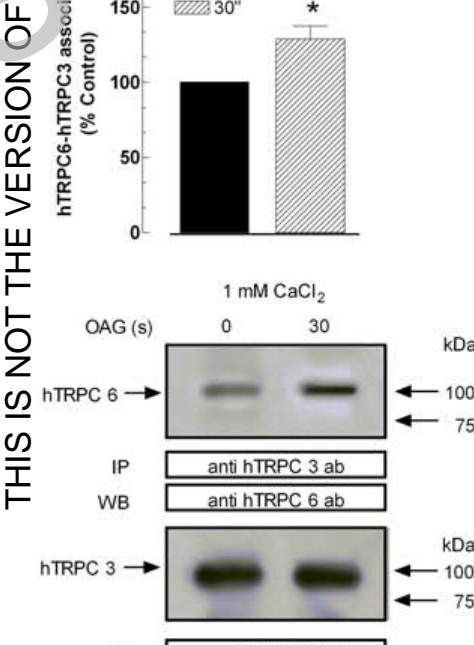

$\begin{aligned} \text { IP } & \text { antihTRPC } 3 \text { ab } \\ \text { WB } & \text { antihTRPC } 3 \text { ab } \\ & \end{aligned}$

H

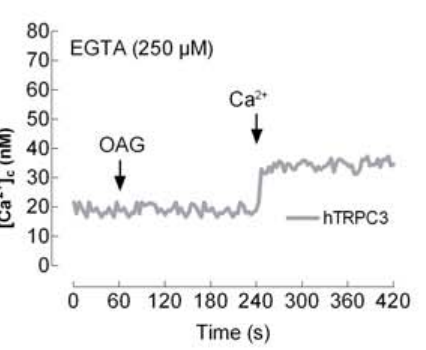

Licenced copy. Copying is not permitted, except with prior permission and as allowed by law.

(C) 2009 The Authors Journal compilation @ 2009 Portland Press Limited 
B Biochemical Journal Immediate Publication. Published on 05 Mar 2009 as manuscript BJ20082179

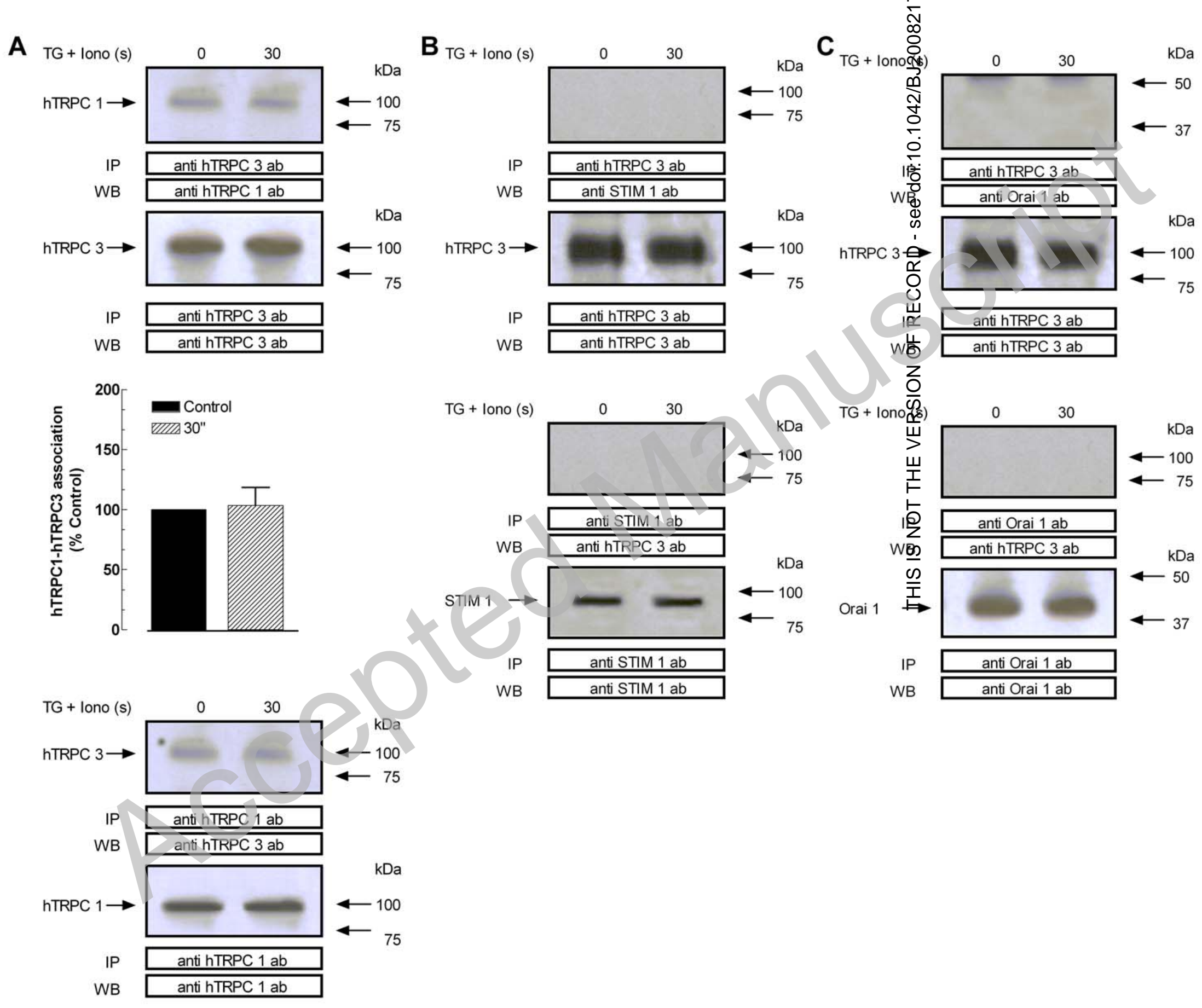

Licenced copy. Copying is not permitted, except with prior permission and as allowed by law. (C) 2009 The Authors Journal compilation ( 2009 Portland Press Limited 


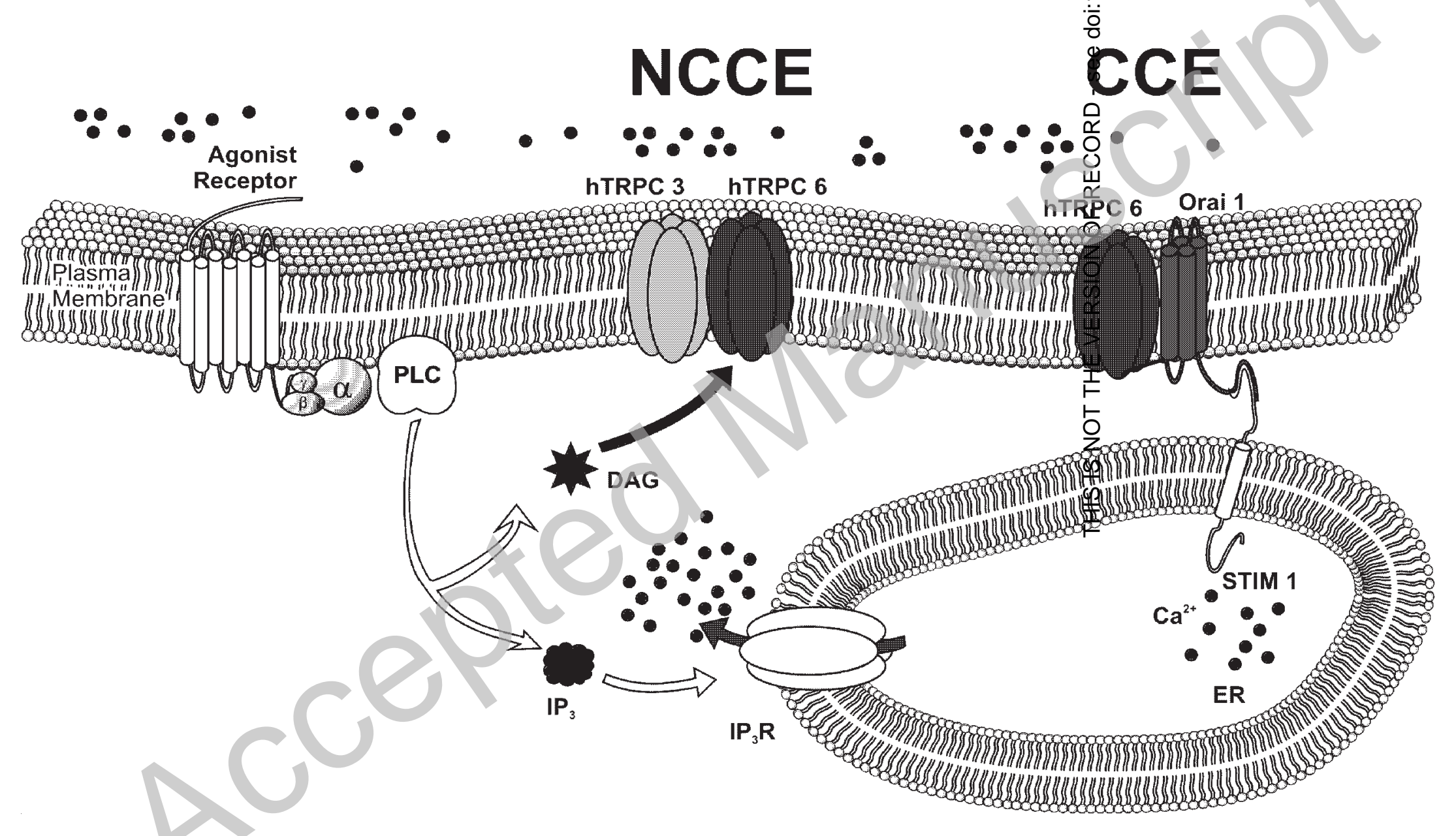

